\title{
Stress Inversion of Regional Seismicity in the Sea of Marmara Region, Turkey
}

\author{
Christopher Wollin, ${ }^{1}$ (D) Marco Bohnhoff, ${ }^{1}$ (D) Václav Vavryčuk, ${ }^{2}$ (D) and Patricia Martínez-Garzón ${ }^{1}$ (D)
}

\begin{abstract}
In this study we derive the stress tensor and its local variations throughout the Marmara region, Turkey. Based on a recently compiled 10-year earthquake catalogue, we directly invert first-motion polarity data and quantify confidence intervals for the principal stress orientations. We find a combined strike-slip and normal faulting stress field for the Marmara region generally reflecting the overall transtensional setting. However, the results clearly show moderate local variations of the stress field. The largest $\left(\sigma_{1}\right)$ and intermediate $\left(\sigma_{2}\right)$ principal stresses show an average regional trend of $\mathrm{N} 125^{\circ} \mathrm{E}$ and locally varying plunges. The least principal stress $\left(\sigma_{3}\right)$ is well resolved in its confidence interval and consistent throughout the region with an average trend of $\sim$ $\mathrm{N} 35^{\circ} \mathrm{E}$ and a subhorizontal plunge. The eastern Sea of Marmara shows local stress field orientations with pronounced strike-slip (northern part) and normal faulting (southern part) components. Along the central Marmara region, normal faulting tends to dominate, while a well resolved strike-slip stress regime is found in the western Sea of Marmara region. Regarding the faulting mechanism of an earthquake with magnitude up to 7.4 which is expected in this area in direct vicinity of the Istanbul metropolitan region, our results imply that neither strike-slip nor normal faulting kinematics can be excluded.
\end{abstract}

\section{Introduction}

The vast majority of earthquakes are caused by failure of critically stressed faults within the seismogenic layer of the earth's crust and along active tectonic plate boundaries (e.g. Wallace 1951; Bott 1959; McKenzie 1969; Vavryčuk 2015; Hardebeck and Okada 2018). Whether a particular fault is going to rupture or not is controlled by the fault's orientation with respect to the present stress field orientation

Electronic supplementary material The online version of this article (https://doi.org/10.1007/s00024-018-1971-1) contains supplementary material, which is available to authorized users.

1 German Research Center for Geosciences, Section 4.2: "Geomechanics and Rheology", Telegrafenberg, 14473 Potsdam, Germany. E-mail: wollin@gfz-potsdam.de

2 Institute of Geophysics of the Czech Academy of Science, Bocni II/1401, 14100 Praha 4, Czech Republic. thereby defining the preferred faulting mechanism to be expected in a future earthquake (Vavryčuk 2011). The Sea of Marmara region in northwestern Turkey is located along the plate-bounding North Anatolian Fault Zone (NAFZ) at the transition zone between the pure right-lateral part of the NAFZ to the east and the north-south extensional Aegean region to its southwest. This setting results in a first-order transtensional tectonic regime (McClusky et al. 2000; Le Pichon et al. 2015; Bohnhoff et al. 2016b) and in the opening of the Sea of Marmara as a pull-apart structure (e.g. Armijo et al. 1999, 2005; Le Pichon et al. 2001). The submarine Marmara segment of the NAFZ currently represents a seismic gap capable of generating a major $(M>7)$ earthquake in the next decades (Parsons 2004; Bohnhoff et al. 2013; Murru et al. 2016). This translates into significant hazard and risk for the neighboring Istanbul metropolitan area with its $15+$ million inhabitants (Bạs and Yăgci 2008). Much progress has been achieved in characterizing the Marmara Section of the NAFZ with regard to potential nucleation points and rupture propagation (e.g. Karabulut et al. 2011; Hergert et al. 2011; Bohnhoff et al. 2013, 2017b). However, in order to quantify the earthquake and potential tsunami risk for the region (e.g. Yalçıner et al. 2002; Hébert et al. 2005; Latcharote et al. 2016), a key role is taken by the expected type of faulting. For its characterization, knowledge of the local and regional stress field orientation is crucial.

In this paper we study the stress field orientation in the broader Marmara region based on the recently published earthquake catalogue of Wollin et al. (2018) which covers the time period of 2006-2016. Since the catalogue does not allow to determine a sufficiently high number of single-event focal mechanisms due to absence of moderate-size $(M>3)$ events, we calculate the stress tensor by a 
direct inversion of first-motion P-wave polarities of seismicity clusters throughout the study region. The resulting uncertainties of the resolved stress are discussed and expressed as intervals or areas of confidence of the marginal probability density functions (PDFs). The reliability of our results is quantified by synthetic modeling. We discuss which type of faulting can be expected for the pending Marmara earthquake and its potential consequences for seismic risk scenarios.

\section{Tectonic Setting of the Marmara Region in NW Turkey}

The North Anatolian Fault Zone (NAFZ) is one of the largest plate bounding transform faults (Ketin 1948). It extends for some $1200 \mathrm{~km}$ between the Karliova triple junction in Eastern Anatolia and the Gulf of Saros in the northern Aegean (e.g. Barka 1992; Şengör et al. 2005; Bohnhoff et al. 2016b) separating the Anatolian and Eurasian plates. Wedged by the northward moving Arabian plate in the east and accelerated by the pull of the southward rollback of the Hellenic subduction zone in the west, the Anatolian plate performs a westward motion in combination with counter-clockwise rotation with respect to Eurasia resulting in a right-lateral strikeslip system along most of its extent (Flerit et al. 2004; Bohnhoff et al. 2005; Reilinger et al. 2006; Bulut et al. 2012). GPS data suggest an average slip rate along the NAFZ of 20-25 mm/year, where values increase towards the west (Reilinger et al. 2006). The pure strike-slip system along the eastern and central NAFZ turns into a transtensional setting in NW Turkey, where the opening of the Sea of Marmara as a large pull-apart structure is a result of the rollback of the Hellenic subduction zone that started a few million years ago, overprinting earlier tectonic units of the region (e.g. Armijo et al. 1999, 2005; Le Pichon et al. 2001; McClusky et al. 2000; Şengör et al. 2005; Le Pichon et al. 2015). This tectonically young development still evolves and leads to the progression of the transtensional system towards the east. Younger and thus less well developed pull-apart structures are currently progressing further east below the eastern tip of the Sea of Marmara (Cinarcik
Basin) (Le Pichon et al. 2001; Karabulut et al. 2002; Acarel et al. 2014) and also extend further on land along the 1999 Izmit rupture (Akyazi Plain) (Bohnhoff et al. 2006; Bulut et al. 2007; Najdahmadi et al. 2016, 2018).

The NAFZ forms a single main fault strand along most of its part between eastern Anatolia and the Bolu region until approximately $150 \mathrm{~km}$ east of the city of Izmit where it splits into two major branches, the northern and the southern NAFZ strand (Le Pichon et al. 2014). Below the Sea of Marmara most of the NAFZs deformation is accommodated by the northern strand (Reilinger et al. 2006; Hergert and Heidbach 2010; Ergintav et al. 2014), also referred to as the 'Marmara Section' (Fig. 1, Wollin et al. 2018). To the east and west, the Marmara Section is bound by the three most recent major regional earthquakes $\left(M_{\mathrm{w}}>7\right)$ : the 1912 Mürefte-Ganos event in the west (Ambraseys 1970; Janssen et al. 2009) and the 1999 Izmit and Düzce events in the east (Tibi et al. 2001; Pinar et al. 2001; Barka et al. 2002; Bohnhoff et al. 2016a) (Fig. 1). The last major earthquake along the Marmara Section occurred in 1766 (M7.4, Ambraseys 1970). Given the average recurrence time of 200-250 years this fault is currently in the final phase of its seismic cycle (Parsons 2004; Bohnhoff et al. 2016b) and thus believed to represent a seismic gap whose activation in a $M_{\mathrm{w}} \geq 7.0$ earthquake threatens the metropolitan area of Istanbul. The two end-members for the potential faulting style of this earthquake discussed in the literature are: (1) a single throughgoing strike-slip event activating the entire so-called "Main Marmara Fault" between the 1912 and 1999 ruptures (Le Pichon et al. 1999, 2001), or (2) an activation of several smaller en-echelon normal faults (Armijo et al. 2002, 2005). While the strike-slip scenario implies intense ground-shaking in succession to a single event with a magnitude of up to 7.4, the normal faulting events could cause local tsunamis as documented in the historic past (Yalçıner et al. 2002).

First information on the stress field orientation in the broader Marmara region was provided by Kiratzi (2002) who inverted focal mechanisms of 12 large regional earthquakes recorded during the second half of the twentieth century, most of which occurred on the mainland surrounding the Sea of Marmara. The 


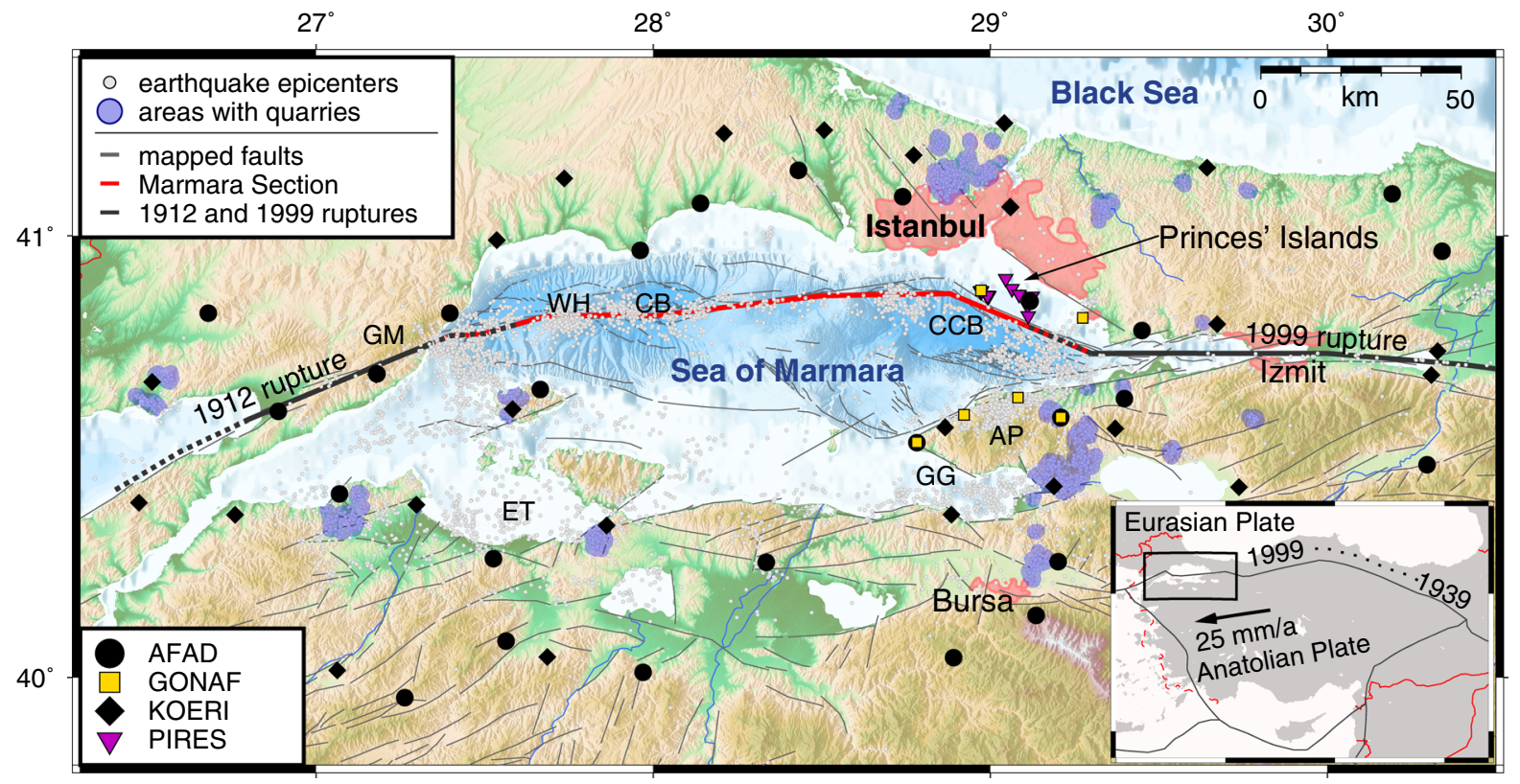

Figure 1

The Sea of Marmara Region with the offshore Marmara Section of the North Anatolian Fault Zone (NAFZ) delineated in red. In its continuation lie the ruptures of the 1912 Ganos and 1999 Izmit earthquakes (delineated in black). Location of topographic features are indicated with capital letters: Western High (WH), Central Basin (CB), Central High (CH), Çınarcık Basin (CCB), Armutlu Peninsula (AP) all after (Bécel et al. 2009), Gulf of Gemlik (GG), Erdek Tombolo (ET), Ganos Mountains (GM) all after (Şengör et al. 2014). Permanent seismic stations are marked by different symbols according to their associated network. The bathymetry, submarine faults and onshore faults are after Le Pichon et al. (2001), Armijo et al. (2005) and the Turkey General Directorate of Mineral Research and Exploration (pers. comm.), respectively. The extent of larger cities (Istanbul, Izmit, Bursa) is indicated by pink areas. The inset in the lower right shows the area of study in the broader tectonic regime where the movement of the Anatolian Plate is given with respect to stable Eurasia. 6812 epicenters of selected seismicity are shown. Events within blue areas are likely to be quarry blasts (after Wollin et al. 2018)

results show a first-order strike-slip stress field with an oblique component. The largest horizontal stress $\left(S_{\text {Hmax }}\right)$ has a WNW-ESE orientation and a transpressional signature. However, also $M>6$ normal faulting earthquakes such as the 1963 Armutlu earthquake below the eastern Sea of Marmara are well documented (Bulut and Aktar 2007). Örgülü (2011) used a refined data set of numerous smaller events and showed that a strike-slip regime can be separated from a normal-faulting regime in the eastern Marmara region between the Princes' Islands Segment in the north and the neighboring Armutlu Peninsula in the south (see Fig. 1 for location). This transition is accompanied by a rotation of $S_{\text {Hmax }}$ from NW-SE to WNW-ESE and correlates well with the results for the fast polarization direction obtained from the shear-wave-splitting analysis (Eken et al. 2013). Here the polarization is sub-parallel to the maximum shortening direction at seismic stations in the Princes' Islands and rather diffuse for those in the Armutlu Peninsula. Similar stress orientations were found by Pinar et al. (2003) who document a pure strike-slip regime with an intermediate shape ratio $R=0.5$ for the entire eastern Sea of Marmara, where the overlap of the confidence areas of the smallest and the intermediate principal stresses, $\sigma_{2}$ and $\sigma_{3}$, indicate a transpressional stress regime. This is in contrast to the results of Örgülü (2011), who document an overlap of the confidence areas of the largest principal stresses, $\sigma_{1}$ and $\sigma_{2}$, thus indicating transtension. At the westernmost tip of the Princes' Islands Segment, Armijo et al. (2002) report on en-echelon normal fault scarps apparently produced by composite normal and strike-slip faulting. In the northern Armutlu Peninsula, normal-faulting with a more pronounced strike-slip component at the south is confirmed by Kinscher et al. (2013). For the Princes' Islands Segment, Armutlu Peninsula and the 
Gulf of Gemlik areas, Öztürk et al. (2015) find a normal-faulting stress regime and a rotation of the minimum horizontal stress $S_{\mathrm{Hmin}}$ from SW-NE to SSW-NNE, along a trajectory from north to south. Interestingly, several reverse mechanisms are reported further west. Strike-slip and normal faulting events generally dominate the offshore segment below the NAFZ, which evidently lacks near-fault observations (Pinar et al. 2003; Örgülü 2011; Wollin et al. 2018). Below the western Sea of Marmara, where the Marmara Section changes strike from E-W to ESE-WNW at the Ganos-Bend, a transpressional stress regime (Armijo et al. 1999, 2002; Pinar et al. 2003; Janssen et al. 2009; Örgülü 2011) or strike slip Öztürk et al. (2015) is reported in the literature.

\section{Data Synthesis and Methods}

\subsection{Earthquake Catalog and Determination of First- Motion Polarities}

Recently, Wollin et al. (2018) combined seismic recordings (2006-2016) from the major permanent networks in the region (black dots in Fig. 1), including the two national networks (AFAD and KOERI), to ensure the best possible azimuthal coverage. This is crucial since the largest portion of the target fault lies below the Sea of Marmara, thus preventing the deployment of on-land near-fault seismic stations needed for the determination of reliable focal mechanisms of small to moderate earthquakes. To compile a waveform data base and subsequent hypocenter catalogue, Wollin et al. (2018) re-picked the entire data set employing a novel automatized picking scheme. The new Marmara hypocenter catalogue reports 6812 reliable hypocenters down to magnitude $M_{\mathrm{w}}=0.7$ for the time period 2006-2016, all of which are based on at least seven picks (including P- and S-picks) and have a maximum azimuthal gap GAP $\leq 270^{\circ}$ as well as an error ellipse area of less than $A_{\text {ell }} \leq 256 \mathrm{~km}^{2}$ (Wollin et al. 2018). In this catalogue, each P-phase onset was assigned a first-motion polarity, if established with a sufficient confidence. Otherwise, the first motion was rated neutral. The signal-to-noise ratio (SNR) was used as a measure for the first-motion uncertainty and
Fig. 2 shows the fraction of the P-wave onsets and first-motion polarities as a function of the SNR threshold. With the SNR threshold equaling 4, slightly more than half of the picks were assigned the first motion (blue distribution in Fig. 2a). In order to obtain a more homogeneous distribution of the first-motion measurements on the focal sphere, we later consider phase onsets measured within an epicentral distance of $\leq 60 \mathrm{~km}$. In this way, we retained $\sim 50 \%$ of all picks, amongst which the fraction of well determined first motions is higher ( $\sim 40 \%$ with respect to all picks, red distribution in Fig. 2a). Nevertheless, Wollin et al. (2018) use 758 reference picks on 72 manually picked earthquakes to calculate the fraction of automatically determined first motions being equal or different to the manually derived values. The result of this analysis yields an error rate with respect to all measurements of $\sim 10 \%$, i.e. on average $\sim 10 \%$ of all up- and down-polarities are erroneously flipped. Figure 3a, b show exemplary $\mathbf{U p}$ and Down first motions (i.e. compressional and dilatational or positive ' + ' and negative '-', respectively) of 75 P-wave onsets each, which were recorded from earthquakes of $M_{\mathrm{w}}$ between 1.7 and 3.8 at epicentral distances between 5 and $210 \mathrm{~km}$.

In this study, we utilize P-wave polarities of 6812 events. In general, the number of measured phase arrivals and first-motion polarities per event positively correlates with the moment magnitude (Fig. 4a, b). The bulk of earthquakes have a magnitude $M_{\mathrm{w}}$ in the range between 1.7 and 2.3 and are located with approximately 20 (P- and S-) phase readings on average. However, these events yield usually only 5 high-quality first-motion polarities. This number is too small to calculate stable single-event focal mechanisms, but may be utilized to determine the stress tensor when directly inverting the combined P-wave polarities from many collocated earthquakes.

\subsection{Clustering of Seismicity and Selection of Polarity Data}

The results from the stress-tensor inversion strongly depend on the grouping of the underlying seismicity when investigating the spatial (or 

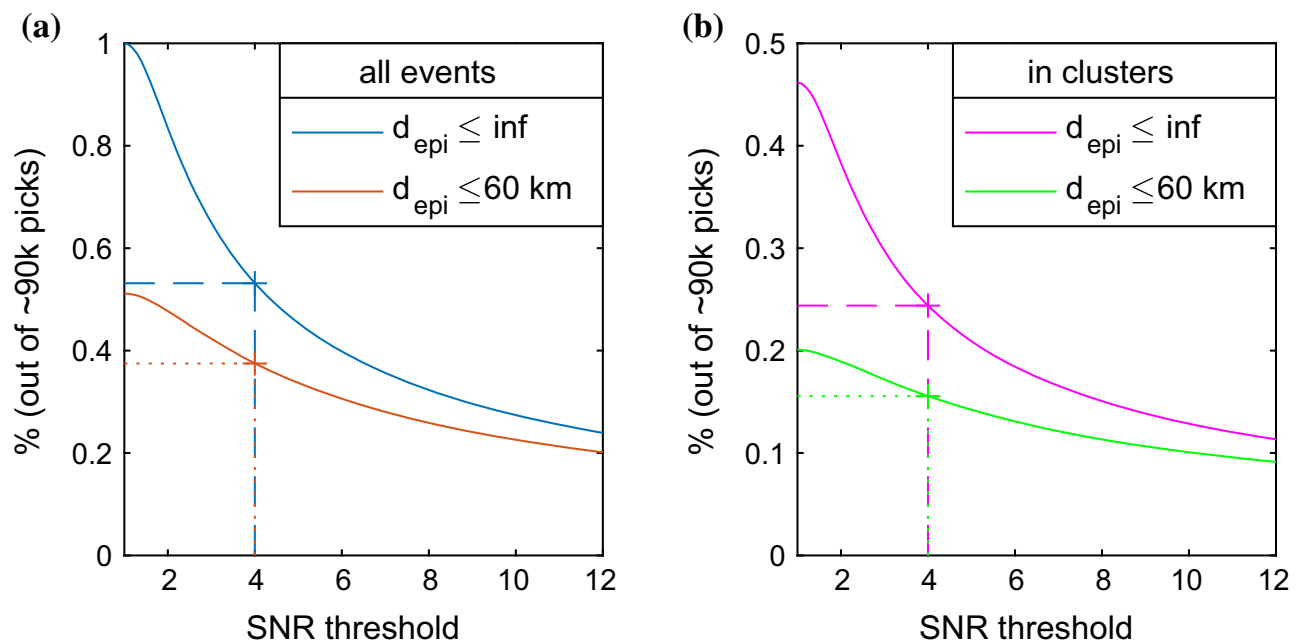

Figure 2

Fraction of $\sim 90,000$ picked P-wave onsets as a function of the threshold for the signal-to-noise ratio (SNR). Picks with SNR $\geq 4$ were assigned an up or down first motion. a Onsets of all earthquakes in the catalog, $\mathbf{b}$ only those associated with a cluster for which the stress tensor was calculated. Both figures differentiate between all onsets and those measured within an epicentral distance of $d \leq 60 \mathrm{~km}$
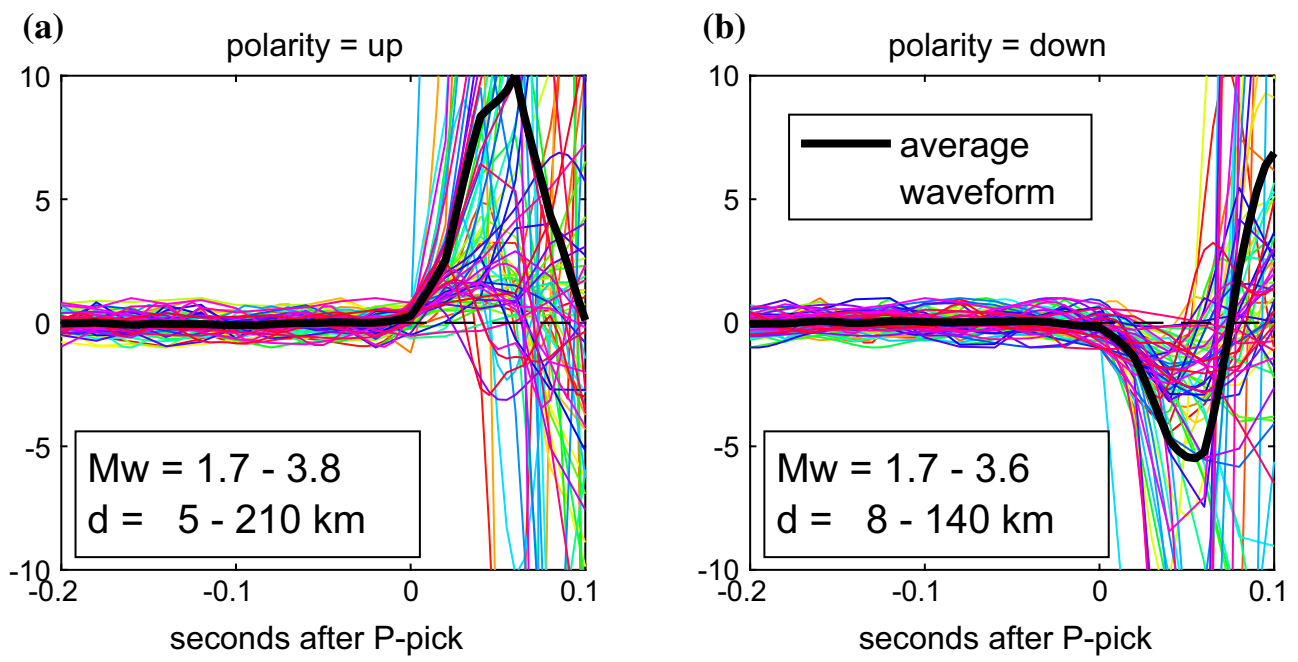

Figure 3

Two sets of 75 exemplary P-wave onsets of events with $M_{\mathrm{w}}$ between 1.7 and 3.8 at epicentral distances $d$ between 5 and $210 \mathrm{~km}$ with a down (negative) and $\mathbf{b}$ up (positive) first motions. The wavelets are normalized to the largest absolute value within $1 \mathrm{~s}$ before the P-wave onset. The black graph shows the averaged wavelet

temporal) variations of the stress tensor (e.g. Hardebeck and Hauksson 1999; Townend and Zoback 2001; Hardebeck and Michael 2006; MartínezGarzón et al. 2013, 2016a; Ickrath et al. 2015; Öztürk et al. 2015 ). In this study, we aim at investigating the stress field orientation along local tectonic features of particular interest as well as in areas with a pronounced spatially clustered seismic activity. We used rectangular polygons to select groups of earthquakes along fault segments and defined seismicity clusters with the 'Density-based spatial clustering of applications with noise' (DBSCAN) method (Ester 

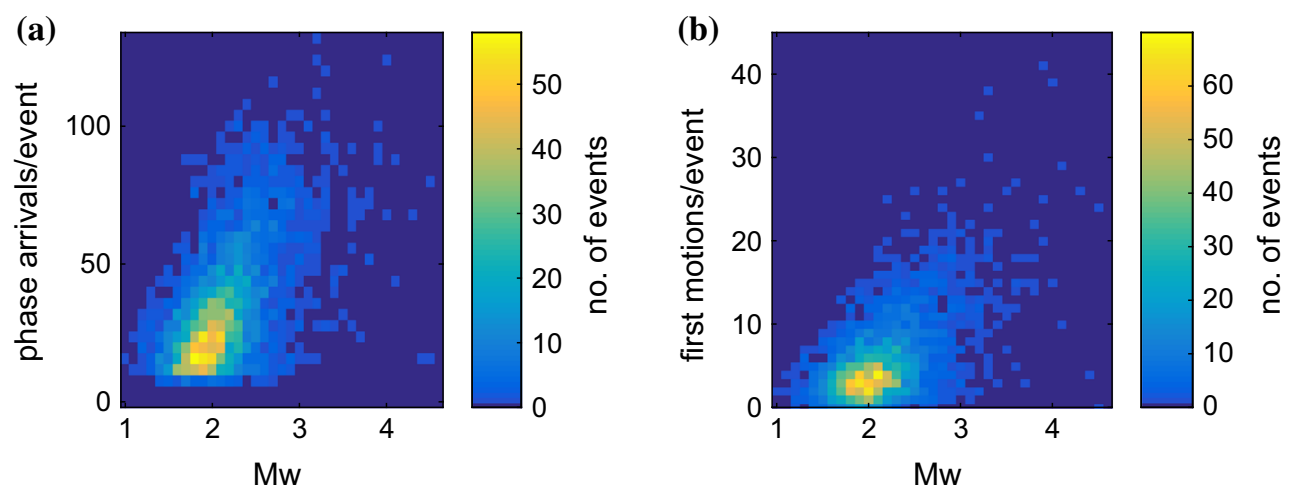

Figure 4

Density plots of the number of earthquakes as a function of two parameters: a the moment magnitude $M_{\mathrm{w}}$ versus the number of phase arrivals (P- and S-waves) used per earthquake location, and $\mathbf{b}$ the moment magnitude $M_{\mathrm{w}}$ versus the number of acceptable "Up" or "Down" firstmotion polarities per earthquake

et al. 1996). This method essentially groups earthquakes according to the density of their occurrence, which is expressed by two parameters, $N_{\mathrm{c}}$ and $r_{\mathrm{c}}$, the minimum number of elements and the maximum distance between elements, respectively. DBSCAN may identify arbitrarily shaped clusters and neither requires the a-priori estimation of the number of expected clusters nor some arbitrary initial clustering ( $k$-means, Han et al. 2011) nor a termination condition (hierarchical clustering, Han et al. 2011). We use the inter-epicentral distance as a metric and choose seven sets of $N_{\mathrm{c}}$ and $r_{\mathrm{c}}$ with decreasing density $\rho_{\mathrm{c}}=\frac{r_{\mathrm{c}}}{N_{\mathrm{c}}}$, thus obtaining 207 nested clusters. The cloud-shaped boundary of a seismicity cluster may be defined by the union of the $r_{\mathrm{c}}$ neighborhoods of all events associated with the respective cluster. For all cluster densities we require a minimum cluster size of $N_{\mathrm{c}}=10$ events. However, clusters of only 10 events are too small for any accurate stress inversion. After the density based clustering we thus add events located in the wider neighborhood of a cluster defined by $r_{\mathrm{c}}+r_{\mathrm{b}}$ (for numeric values of the parameters see Table 1). Some clusters contain a similar subset of events and we only kept the largest representative and only those clusters which contain between 100 and 1000 events (see Appendix 1 for more details regarding the usage of DBSCAN in this study and examples of the cloud-shaped cluster boundaries in dependence of different parameter sets in Fig. 14). In this way we obtain a set of 20 nested and overlapping clusters representing earthquake agglomerations of
Table 1

DBSCAN parameters used in this study to cluster seismicity in the Sea of Marmara Region

\begin{tabular}{lllll}
\hline$\#_{\text {DBSCAN }}$ & $N_{\mathrm{c}}$ & $r_{\mathrm{c}}$ & $\rho_{\mathrm{c}}$ & $r_{\mathrm{b}}$ \\
\hline 1 & 10 & 0.8 & 1.99 & 1.6 \\
2 & 10 & 1.0 & 1.59 & 1.0 \\
3 & 10 & 1.3 & 1.22 & 1.0 \\
4 & 10 & 1.5 & 1.06 & 1.5 \\
5 & 10 & 1.7 & 0.94 & 1.3 \\
6 & 10 & 2.5 & 0.64 & 0.5 \\
7 & 10 & 4.0 & 0.40 & 0.0 \\
\hline
\end{tabular}

The minimum number of events in a cluster, $N_{\mathrm{c}}$, within a radius $r_{\mathrm{c}}$ (in $\mathrm{km}$ ) constitute the average epicentral density in a seismicity cluster, $\rho_{\mathrm{c}}$. Radius $r_{\mathrm{b}}$ is added to $r_{\mathrm{c}}$ (in $\mathrm{km}$ ) to "blow up" the cluster boundary and to include some of the surrounding seismicity

different epicentral density and distributional scale, potentially suitable for a stress-tensor inversion. We include three seismogenic volumes by defining longitudinal and latitudinal intervals delineating crucial portions of the Marmara Section, from east to west, namely the western Basins, the central Marmara Section and the Princes' Islands Segment.

The stress-tensor inversion using the first-motion polarities requires a uniform sampling of the focal sphere. Refracted P-wave rays are emitted within narrow angle intervals and they tend to form dense concentric rings when mapped onto the focal sphere. Therefore, we predominantly used upward radiated (e.g. direct) rays for the inversion. For a source at $12 \mathrm{~km}$ depth, which is an average depth of the seismicity in the Marmara region, the velocity model of Karabulut et al. 
(2011) predicts direct rays up to an epicentral distance of $50 \mathrm{~km}$. Thus, we only processed the first-motion polarities measured along the ray paths covering epicentral distances of less than $60 \mathrm{~km}$ and emerging from events in the depth interval of 8-16 km. This procedure significantly decreases the available firstmotion measurements (Fig. 2b) but produces more reliable results for the resolved stress tensor.

In order to avoid oversampling of rays measured by densely collocated seismic stations, we assigned the corresponding first motion to one station, if more than $3 / 4$ of the first motions measured at the neighboring stations have the same sign. In the eastern Sea of Marmara, this affected the PIRES (Bohnhoff et al. 2013) and the GONAF (Bohnhoff et al. 2017a) networks, which consist of several dense near-fault seismograph arrays. The PIRES network includes local five-station arrays on the islands of Yassiada and Sivriada in direct vicinity to the Princes' Islands Segment as part of the Marmara Section (Fig. 1). Furthermore, the GONAF vertical arrays are distributed throughout the eastern Sea of Marmara region in near-shore locations or on the Princes' Islands (Sivriada and Büyakada) (Fig. 1). We processed earthquake clusters only if they contained more than 250 reliable first-motion polarities. In this way, we remained with 18 seismicity clusters which consisted of 37-310 earthquakes and yielded between 256 and 3118 first-motion polarities.

\subsection{Inversion for Stress from First-Motion Polarities}

The local stress tensor is inverted from data of the spatial seismicity clusters and the selected fault branches using software package MOTSI (First MOTion Polarity Stress Inversion) of Abers and Gephart (2001). The stress field is described by the normalized deviatoric stress tensor and the MOTSI performs a non-linear inversion with two nested grid searches. The outer search loops over the parameter space of the principal stress axis orientations and the shape ratio

$$
R=\frac{\sigma_{2}-\sigma_{1}}{\sigma_{3}-\sigma_{1}}
$$

where $\sigma_{1} \geq \sigma_{2} \geq \sigma_{3}$ are the principal stress magnitudes and their positive values mean compression
(Zoback 2007). For every possible stress tensor, Abers and Gephart (2001) calculate a set of "stress consistent focal mechanisms" and select the best synthetic focal mechanisms fitting the first-motion polarities of an individual event. The fit of observations to each imposed stress field is expressed by a score, which translates into marginal PDFs for the stress field orientations and the shape ratio. The method is not capable of determining absolute stress values.

The advantage of the approach proposed by Abers and Gephart (2001) is that it circumvents uncertainties, which are usually inherent in the determination of focal mechanisms and which are typically not less than $10^{\circ}$ regarding the orientation of either of the fault planes (e.g. Bohnhoff et al. 2004). Focal mechanisms are particularly uncertain for $M<3.5$ earthquakes, which constitute the bulk of events used in this study (Fig. 4). Thus, the approach allows to include individual events with only few reliable first-motion polarities that would not lead to a reliable single-event focal mechanism otherwise. The possibility of determining the stress field from such events with $M \leq 3$ was confirmed by, e.g. Robinson and McGinty (2000) and Ickrath et al. (2015).

We investigate how well the input data match the theoretical prediction of a synthetic first-motion distribution consistent with the stress tensor retrieved during the inversion. Uncertainties in the stress field parameters, which are expressed as marginal PDFs, may stem from: (1) insufficient observational constraints, for instance in the case of a limited directional diversity of recorded ray coverage, (2) inaccurate first-motion measurements, (3) deviations from the assumption of stress-field homogeneity within the considered cluster area, or (4) a nonnegligible stress interaction between the events. Under the premise that MOTSI maximizes the fit of the searched stress-field parameters to the underlying first-motion data-set, we may quantify the adequacy of our input data with respect to the combined effects of (2)-(4).

Theoretical first-motion distributions were calculated following an approach of Vavryčuk (2011). The approach can be summarized as follows: whereas Abers and Gephart (2001) consider all possible plane 
(a) Observed

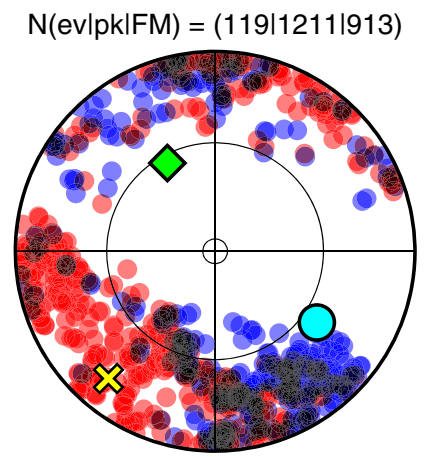

(b) Synthetic (confined)

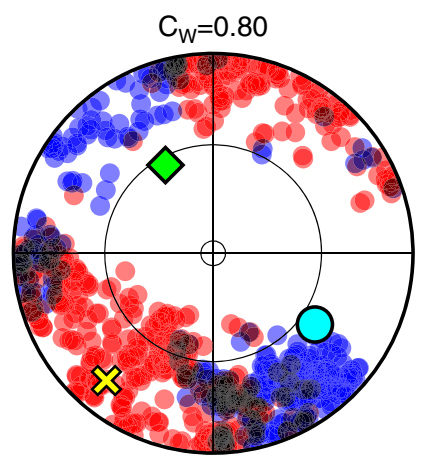

(c) Synthetic (uniform)

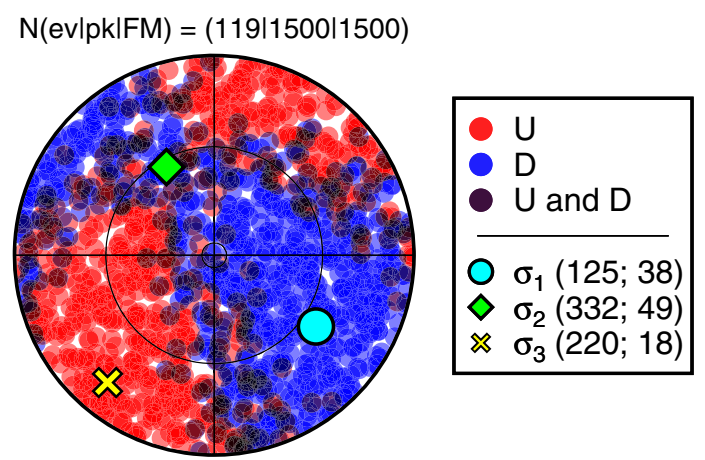

Figure 5

Distributions of up and down first motions on the lower hemisphere in equal-area projection. a 913 first motions out of 1211 picked P-wave arrivals observed along the Princes' Islands Segment for a total of 119 seismic events. b, c Synthetically calculated first motion distributions consistent with the stress tensor, which was obtained from the inversion of the data shown in $\mathbf{a}$. Azimuths and takeoff-angles in $\mathbf{b}$, $\mathbf{c}$ are confined to those observed (913 in total) and uniformly distributed (1500 in total), respectively

orientations as potentially activated, Vavryčuk (2011) restricts the variety of potentially activated faults to orientations satisfying the Mohr-Coulomb failure criterion and assumes activation of a representative set of such critically stressed faults (also see Vavryčuk 2014; Martínez-Garzón et al. 2016b). The first-motion polarities along the combined rays of all sources yield polarity distributions which are characterized by three types of areas: the first and second areas display only positive and negative first motions, respectively, and the third area shows an overlap of both (Fig. 5c). This overlap is due to the first motions belonging to seismic events activated with a variety of different focal mechanisms. The details as well as examples of first-motion distributions in dependence of the shape ratio $R$ are presented in Appendix 2.

We obtained synthetic first-motion distributions by calculating polarities along measured ray paths with respect to the stress field retrieved by MOTSI. A measured distribution and the corresponding synthetic first-motion distribution are shown in Fig. 5a, b. For the quantitative comparison of both distributions, we perform a weighted cross-correlation (see Appendix 3), where the correlated vectors are composed of the differences of fractions of up and down polarities (Eqs. 4, 5). A difference of fractions of up and down polarities was evaluated along uniformly distributed directions, where each difference of fractions may take any value between -1 and 1 . Compared to a normal cross-correlation, the weighted cross-correlation $C_{\mathrm{W}}$ (Eq. 6) puts more emphasis on areas of the focal sphere, which are more densely populated by measured first motions, thus reducing the uncertainty of the corresponding difference of fractions. A correlation with a random first-motion distribution throughout the focal sphere would yield $C_{\mathrm{W}}=0$. Areas of two first-motion distributions with opposing differences of fractions of up and down first motions yield negative contributions, such that $C_{\mathrm{W}}<0$ express dissimilarity. Values of $C_{\mathrm{W}}$ larger than 0.5 display a significant similarity.

\section{Results and Discussion}

We calculated the deviatoric stress tensor for a number of spatial seismicity clusters following the previously described methodology. In the following, we present and discuss the results for the individual study areas. First, we analyze the Princes' Islands Segment, for which we provide all methodological details. Then, we present the results for all other analyzed regions.

\subsection{The Princes' Islands Segment}

Seismicity along the Princes' Islands Segment is distributed along a $\sim 50 \mathrm{~km}$ long and $\sim 10 \mathrm{~km}$ wide stripe (Fig. 6) parallel and south of the fault escarpment, which strikes WNW-ESE. The seafloor 


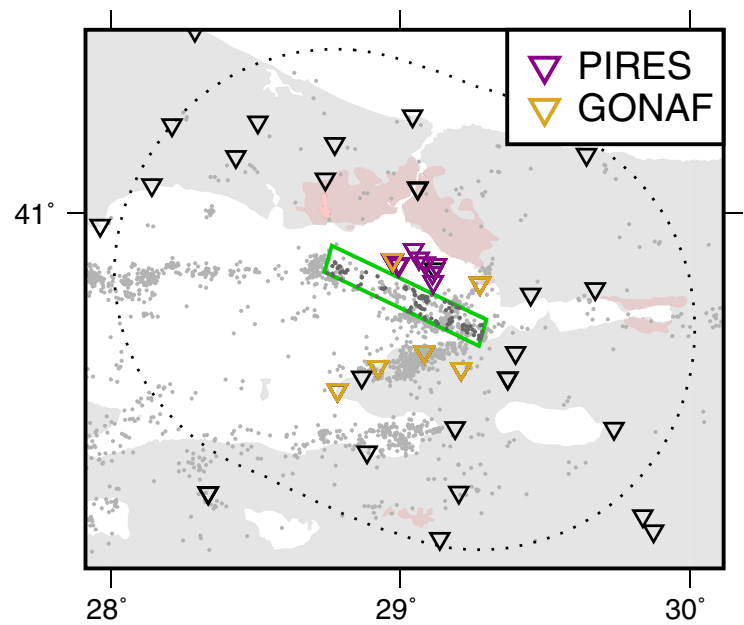

Figure 6

Map of the Princes' Islands Segment with the investigated volume delineated by a colored boundary. The contained seismicity used for the inversion is plotted in darker gray. First motions were only considered if measured at a station within $60 \mathrm{~km}$ epicentral distance. The corresponding stations (triangles) are situated within the dotted boundary. The permanent seismic networks with densely spaced stations, PIRES and GONAF, are marked by colored triangles

expression of this fault segment is situated only $\sim 5$ km south of the Princes' Islands (Figs. 1, 6; Bohnhoff et al. 2013; Wollin et al. 2018). This fault covers a prominent part of the Marmara seismic gap as it is situated in close proximity to Istanbul. It has been found to host a locked fault patch and thus represents a potential nucleation point of the pending Marmara earthquake (Bohnhoff et al. 2013; Ergintav et al. 2014; Wollin et al. 2018). The stress tensor inversion for this area was based on a total of 913 first-motion polarities of 119 local earthquakes spread along the fault. Due to the seismic gap, the epicentral distribution displays large earthquake densities at the northwestern and southeastern tip of the segment. For this reason, the DBSCAN either associates the tips to different clusters or merges them along with seismicity agglomerations further to the south-east. In order to jointly investigate the stress field along the entire Princes' Islands Segment, we select seismicity located within a polygon of the above given measurements and recorded by $\sim 30$ stations (Fig. 5a).

The orientations of the largest $\left(\sigma_{1}\right)$ and smallest $\left(\sigma_{3}\right)$ principal stress axes are given by the global maxima of the marginal PDFs obtained with MOTSI and $\operatorname{read}(\mathrm{az}, \mathrm{pl})_{\sigma_{1}}=\left(125^{\circ}, 38^{\circ}\right)$ and $(\mathrm{az}, \mathrm{pl})_{\sigma_{3}}=$ $\left(220^{\circ}, 18^{\circ}\right)$ (Fig. 7), thus constraining $(\mathrm{az}, \mathrm{pl})_{\sigma_{2}}=$ $\left(332^{\circ}, 49^{\circ}\right)$. The area delineated by the $95 \%$ confidence limit of the $\sigma_{3}$-axis orientation, $A_{95 \%}\left(\sigma_{3}\right)$, is small and bounded to an approximately circular patch showing that the $\sigma_{3}$-axis is well resolved. By contrast, the orientation of the $\sigma_{1}$-axis is less well resolved as indicated by the shape and size of the corresponding area of confidence, $A_{95 \%}\left(\sigma_{1}\right)$ (for the size, also see Table 2). The trend is well bound along
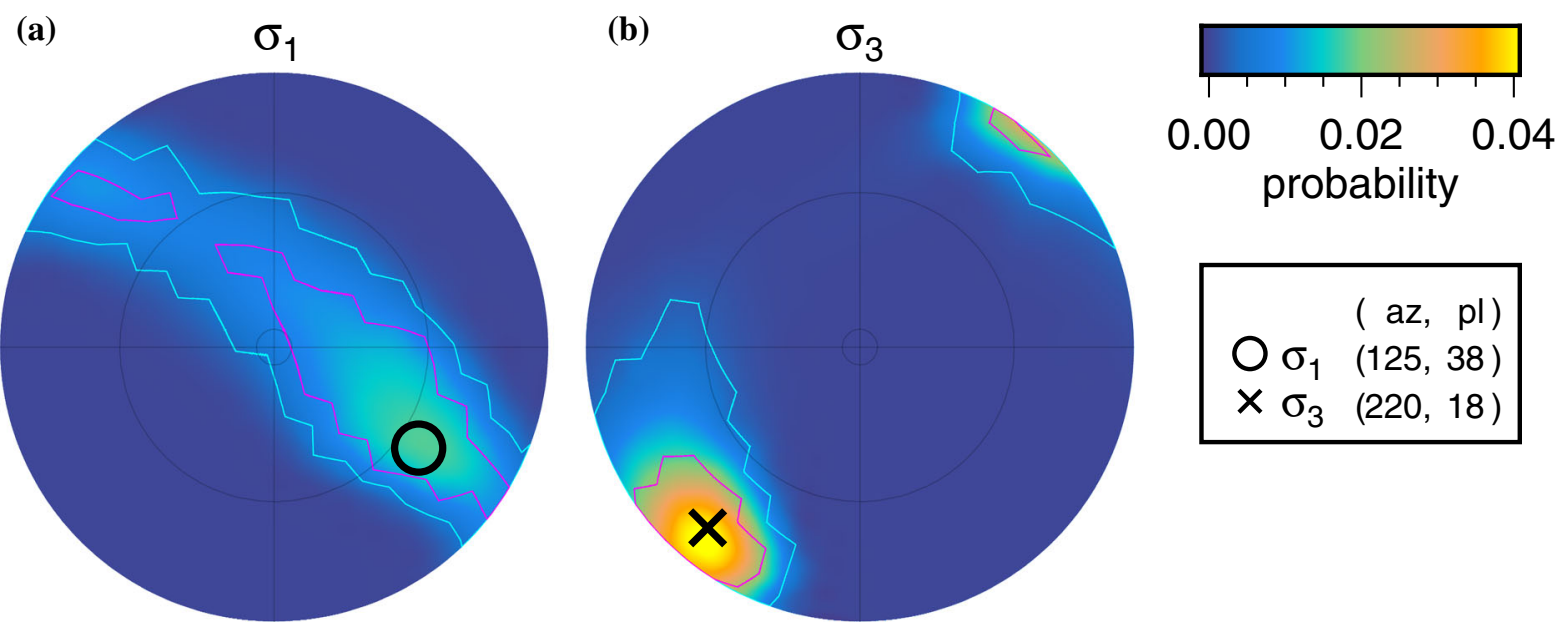

Figure 7

Marginal probability distributions of orientations of the $\sigma_{1}$ and $\sigma_{3}$ principal stress axis on the lower hemisphere in equal area projection calculated for seismicity at the Princes' Islands Segment (Fig. 6). Contour lines delineate the 68 and $95 \%$ confidence limits where the color scheme is as in Fig. 8 
Table 2

Stress-tensor results for individual clusters

\begin{tabular}{|c|c|c|c|c|c|c|c|c|c|c|c|c|c|c|c|}
\hline \# & Abrev. & Name & $N_{\text {events }}$ & $N_{\text {Picks }}$ & $N_{\mathrm{FMs}}$ & $C_{\mathrm{W}}$ & $a z_{\sigma_{1}}$ & $p l_{\sigma_{1}}$ & $A_{95 \%}\left(\sigma_{1}\right)$ & $a z_{\sigma_{3}}$ & $p l_{\sigma_{3}}$ & $A_{95 \%}\left(\sigma_{3}\right)$ & $R$ & $\Delta_{95 \%}(R)_{l, r}$ & $\#_{\text {DBSCAN }}$ \\
\hline 1 & WH & Western High & 64 & 538 & 405 & 0.88 & 134 & 67 & 0.49 & 29 & 2 & 0.34 & 0.5 & $-0.4,0.4$ & 1 \\
\hline 2 & WC1 & $\begin{array}{l}\text { Western High to Central } \\
\text { Basin } 1\end{array}$ & 72 & 602 & 453 & 0.82 & 126 & 59 & 0.48 & 215 & 3 & 0.33 & 0.5 & $-0.4,0.4$ & 6 \\
\hline 3 & WCw & $\begin{array}{l}\text { Western High to Central } \\
\text { Basin wide }\end{array}$ & 79 & 657 & 493 & 0.86 & 126 & 59 & 0.48 & 215 & 3 & 0.33 & 0.5 & $-0.4,0.4$ & $\mathrm{NaN}$ \\
\hline 4 & CMS & Central Marmara Section & 138 & 1263 & 965 & 0.78 & 141 & 44 & 0.44 & 215 & 3 & 0.29 & 0.5 & $-0.4,0.4$ & $\mathrm{NaN}$ \\
\hline 5 & CCB & Cinarcik Basin & 52 & 550 & 435 & 0.67 & 326 & 35 & 0.57 & 223 & 2 & 0.60 & 0.5 & $-0.4,0.5$ & 6 \\
\hline 6 & PIS & Princes' Islands Segment & 119 & 1211 & 913 & 0.81 & 125 & 38 & 0.36 & 220 & 18 & 0.22 & 0.5 & $-0.5,0.3$ & $\mathrm{NaN}$ \\
\hline 7 & EM & Eastern-Marmara & 310 & 3118 & 2484 & 0.76 & 122 & 31 & 0.31 & 213 & 11 & 0.12 & 0.4 & $-0.3,0.4$ & 6 \\
\hline 8 & YT & Yalova-Tuzla & 155 & 1584 & 1223 & 0.85 & 114 & 35 & 0.37 & 213 & 11 & 0.18 & 0.4 & $-0.4,0.4$ & 5 \\
\hline 9 & YC & Yalova Coast & 43 & 412 & 326 & 0.86 & 122 & 31 & 0.50 & 22 & 7 & 0.40 & 0.5 & $-0.5,0.4$ & 4 \\
\hline 10 & YTm & Yalova-Tuzla (medium) & 56 & 554 & 392 & 0.84 & 117 & 43 & 0.45 & 211 & 18 & 0.37 & 0.5 & $-0.5,0.4$ & 4 \\
\hline 11 & YTs & Yalova-Tuzla (small) & 39 & 389 & 282 & 0.79 & 121 & 51 & 0.49 & 211 & 18 & 0.42 & 0.5 & $-0.5,0.4$ & 3 \\
\hline 12 & AP2 & Armutlu 2 & 104 & 1007 & 839 & 0.86 & 306 & 67 & 0.41 & 14 & 12 & 0.32 & 0.5 & $-0.4,0.4$ & 2 \\
\hline 13 & AP1 & Armutlu 1 & 79 & 753 & 627 & 0.83 & 328 & 65 & 0.45 & 213 & 11 & 0.33 & 0.5 & $-0.4,0.4$ & 1 \\
\hline 14 & GGm & Golf of Gemlik (medium) & 37 & 310 & 256 & 0.61 & 121 & 51 & 0.48 & 198 & 9 & 0.45 & 0.5 & $-0.5,0.4$ & 6 \\
\hline 15 & GGI & Gulf of Gemlik (large) & 42 & 351 & 285 & 0.72 & 121 & 51 & 0.49 & 200 & 1 & 0.42 & 0.5 & $-0.4,0.4$ & 7 \\
\hline 16 & ET & Erdek Tombolo & 74 & 679 & 499 & 0.91 & 305 & 14 & 0.44 & 37 & 5 & 0.39 & 0.5 & $-0.4,0.5$ & 7 \\
\hline 17 & G2MI & Ganos to Marmara Island & 102 & 871 & 682 & 0.79 & 128 & 8 & 0.31 & 232 & 24 & 0.40 & 0.5 & $-0.3,0.4$ & 4 \\
\hline 18 & GF3 & Ganos Fault 3 & 86 & 741 & 583 & 0.76 & 135 & 14 & 0.32 & 232 & 24 & 0.40 & 0.5 & $-0.3,0.4$ & 3 \\
\hline
\end{tabular}

The rows are sorted according to the insets' appearance in clockwise sense in Fig. 12, beginning with the inset in the upper left corner. Azimuths $(a z)$ and plunges $(p l)$ are given in degrees $\left({ }^{\circ}\right) . A_{95 \%}$ is the fraction of the area on the unit sphere that the $95 \%$ confidence limits of the stress axis $\sigma_{1}$ and $\sigma_{3}$ occupy, and $\Delta_{95 \%, l / r}$ are the left and right limits of the $95 \%$ confidence interval of the shape ratio $R$. The column \# DBSCAN identifies the parameters used during the density-based clustering to define the local selection of seismic events (Table 1). Manual selection of the seismicity is marked by $\mathrm{NaN}$

$\left(\mathrm{N} 125^{\circ} \pm 10^{\circ} \mathrm{E}\right)$, but the plunge is more uncertain. The marginal PDF for the shape ratio has a maximum at $R=0.5$. The $95 \%$ confidence intervals stretch widely being skewed towards lower values, namely the left and right confidence limit reach zero and 0.8 , respectively (Fig. 8).

In a mixed normal and strike-slip faulting, i.e. transtensional, environment, low values of $R$ indicate similar magnitudes of $\sigma_{1}$ and $\sigma_{2}$. Vanishing $R$ is equivalent to $\sigma_{1}=\sigma_{2}$ (Eq. 1) and would mean that the orientations of the $\sigma_{1}$ and $\sigma_{2}$ axes are not uniquely defined. Consequently, values of $R<0.5$ lead to an elongated area of confidence for the $\sigma_{1}$-axis (which develops into a ring of constant probability in the limit of $R=0$ ) and a value of $R=0.5$ should yield circular areas of confidence for both $\sigma_{3}$ and $\sigma_{1}$ axis. The elongated marginal PDF of $\sigma_{1}$ might also be caused by missing observations along a ring-like area of the focal sphere. However, the trend of the $\sigma_{1}$-axis marginal PDF and the ring-like observational gap are noticeably different and the latter might thus only impede the proper numeric constraint of $R$.

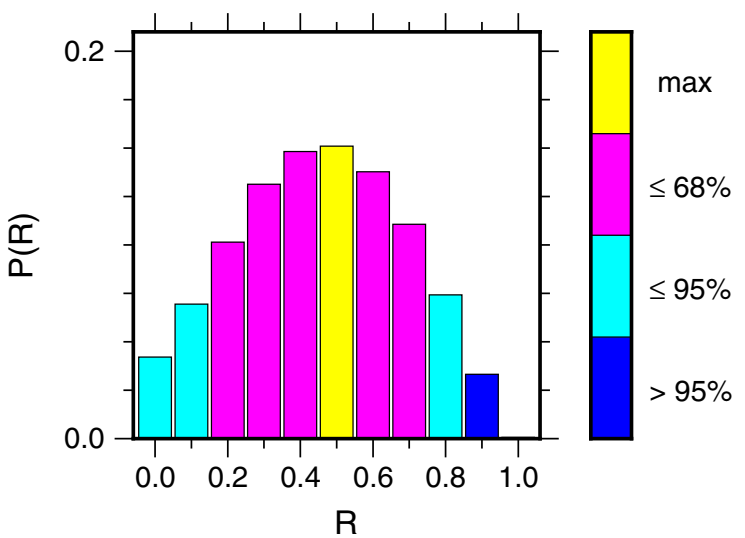

Figure 8

Marginal probability distribution of the shape ratio $R$ for seismicity at the Princes' Islands Segment (Fig. 6). Bar colors indicate the extent of the 68th and 95th percentiles

In order to investigate the resolution of the stress tensor recovered for the Princes' Islands Segment, we performed additional numerical tests. We perturbed the stress-axes orientations and the shape ratios and calculated synthetic first-motion distributions (Fig. 9). 


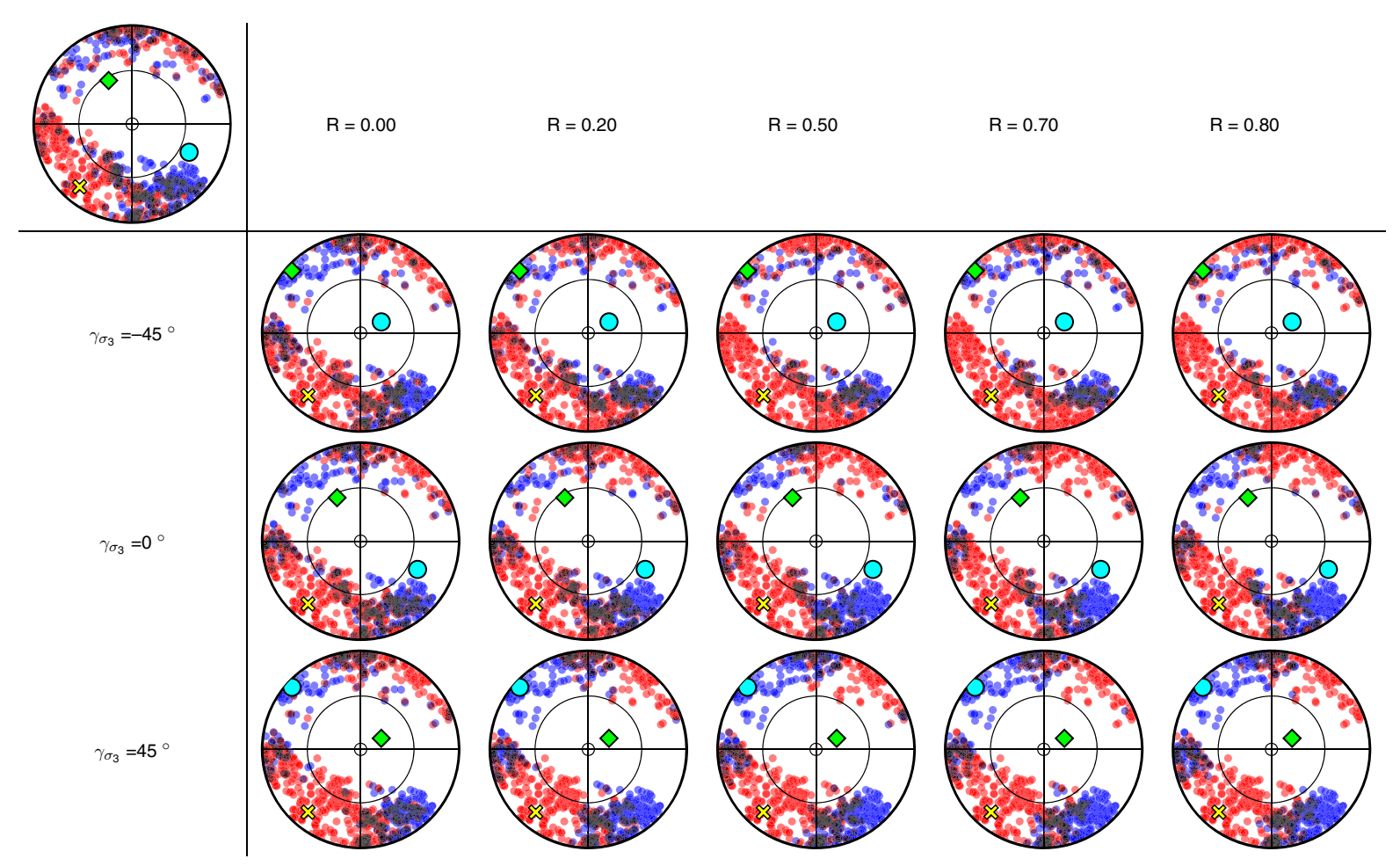

Figure 9

Simulated first-motion distributions representing different stress tensors with the same ray coverage as for observations. The stress axes are marked as in Fig. 5. Columns and rows show different shape ratios and different stress-axes orientations rotated round the $\sigma_{3}$-axis by the angle $\gamma_{\sigma_{3}}$. The measured first-motion distribution and the stress axes retrieved from measurements are shown in the upper left panel

These were again inverted using the MOTSI-software package. The simulated stress tensors had shape-ratios varying from $R=0$ to $R=0.8$ (corresponding to the 68 and $95 \%$ confidence intervals of the marginal probability distribution of $R$ shown in Fig. 8) and stress axes which were rotated by $45^{\circ}$ around the well resolved and thus fixed $\sigma_{3}$-axis. The first motions were evaluated along the observed rays and, before the inversion, $10 \%$ were randomly selected and their polarities reversed.

The results are summarized in Fig. 10 and show that the direction of the $\sigma_{3}$ is accurately retrieved in all cases. The direction of the $\sigma_{1}$ is well retrieved in all cases except for the $R=0$ when the $\sigma_{1}$ and $\sigma_{2}$ have the same values and their directions cannot, in principal, be determined uniquely. However, the correct value of the shape ratio $R$ is not retrieved in most cases. The histograms display a stable pattern with its maximum around $R=0.5$ irrespective of the imposed value of $R$. This is an indication that the histograms are misleading and we will not present them when studying other fault segments in the Sea of Marmara. As seen from Fig. 10, some indication about the value of $R$ is provided by the shape of the confidence areas of the $\sigma_{1}$-axis. This is expressed in a smeared and ring-like shaped $68 \%$ confidence area as for $R=0$ and nearly horizontal $\sigma_{1}$.

Between the synthetic first-motion distribution obtained on the bases of the stress-inversion result and the corresponding measured distribution, the weighted cross-correlation coefficient reads $C_{\mathrm{W}}=$ 0.81 expressing a high similarity. The remaining differences may have three reasons: (1) we expected $10 \%$ of false polarities (Sect. 3.1). In a first-motion distribution composed of many different seismic events, false polarities can be identified in areas that are otherwise strictly dominated by the opposite first motion, e.g. a single down first motion was falsely determined in the south-east near zero plunge (Fig. 5a). (2) Systematic differences may be attributed to a violation of the stress homogeneity. (3) The shape ratio $R$ was badly resolved by the inversion. 


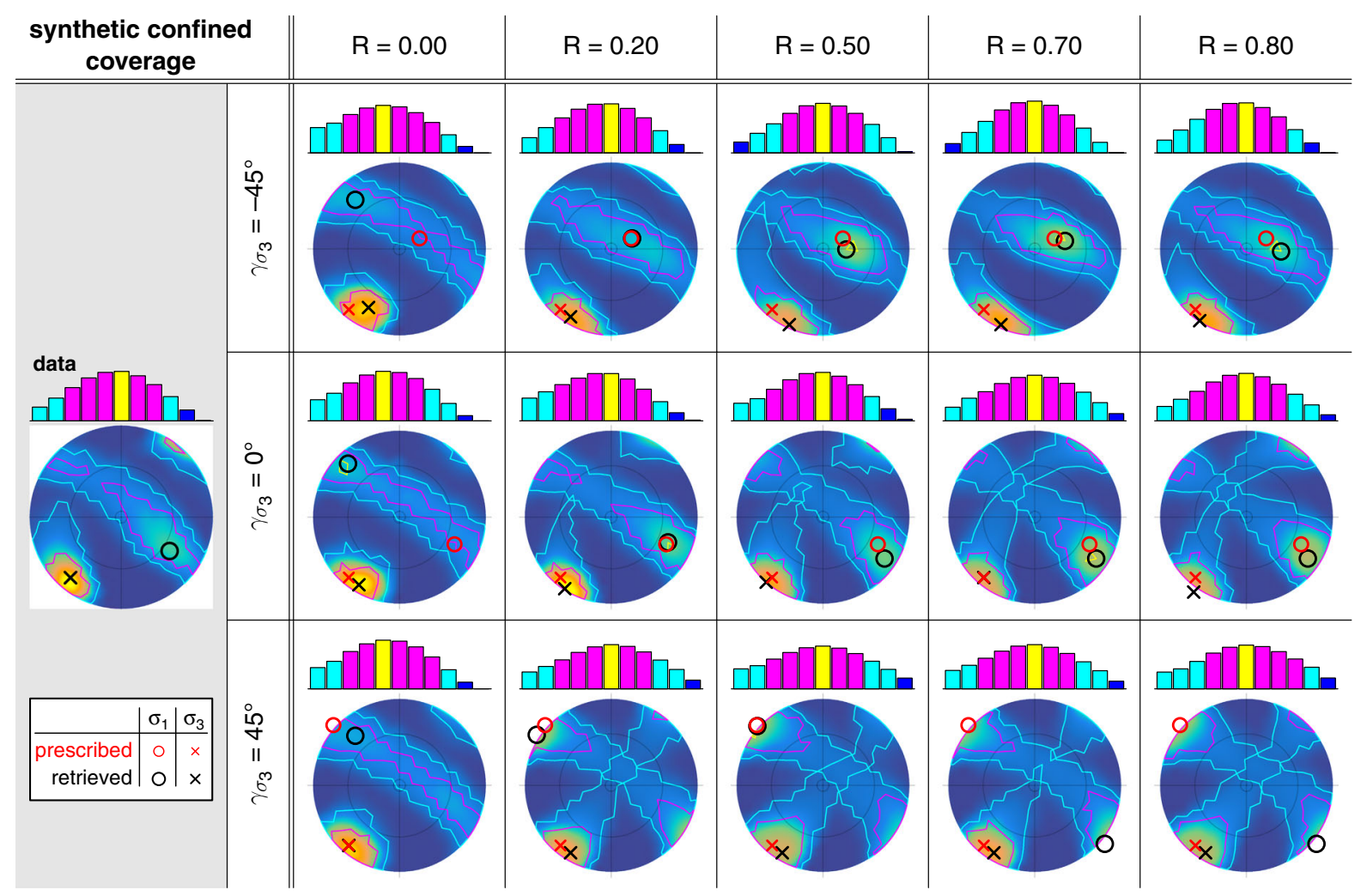

Figure 10

Stress-tensor inversions of the simulated first-motion distributions shown in Fig. 9 where the marginal PDFs of $\sigma_{1}$ and $\sigma_{3}$ are combined. The prescribed and retrieved stress axes are indicated by red and black symbols, respectively. The stress tensor inverted from the measured data is shown in the left column

Figure 15 in Appendix 2 shows that the largest change in the difference of fractions of up and down first motions occurs in the neighborhood of the piercing point of the $\sigma_{2}$-axis. For the first-motion distribution inverted for the Princes' Islands Segment, this area lies near the observational gap described above and thus might explain the poorly resolved shape ratio. However, a low shape ratio also provokes a broad overlap of areas with up and down first motions as observed here.

In summary, the synthetic and measured firstmotion distributions display a large similarity along the Princes Islands Segment. This verifies the inversion results for the stress-axis orientations, particularly for the well constrained $\sigma_{3}$-axis. The differences between the measured and simulated firstmotion distributions are rather systematic and cannot be explained by erroneous polarities. They more likely originate in an inaccurate recovery of the shape ratio $R$ or an inhomogeneous stress field. The $\sigma_{1}$-axis displays a strike-slip orientation with a slight normal component and its smeared $68 \%$ confidence area indicates a transtensional stress regime.

These results imply that neither a pure strike-slip nor pure normal faulting can be predicted for the pending activation of the Princes' Islands Segment. They are in agreement with the stress tensor orientation of this region directly after the 1999 Izmit earthquake (Bohnhoff et al. 2006). The stress field orientation recovered along the Princes Islands Segment is generally congruent with earlier findings by Örgülü (2011) who also report transtension ${ }^{1}$ and a sub-horizontal NE-SW orientation of the $\sigma_{1}$-axis including a minor normal component. The NW-SE striking $\sigma_{3}$-axis reported here is also in accordance with observations by Öztürk et al. (2015). Their results for the $\sigma_{1}$-axis, however, show a vertical

\footnotetext{
${ }^{1}$ Using (a different definition than us) $R=\frac{\sigma_{2}-\sigma_{3}}{\sigma_{1}-\sigma_{2}}$, Örgülü (2011) observes $R \approx 0.7$ for the entire Sea of Marmara.
} 


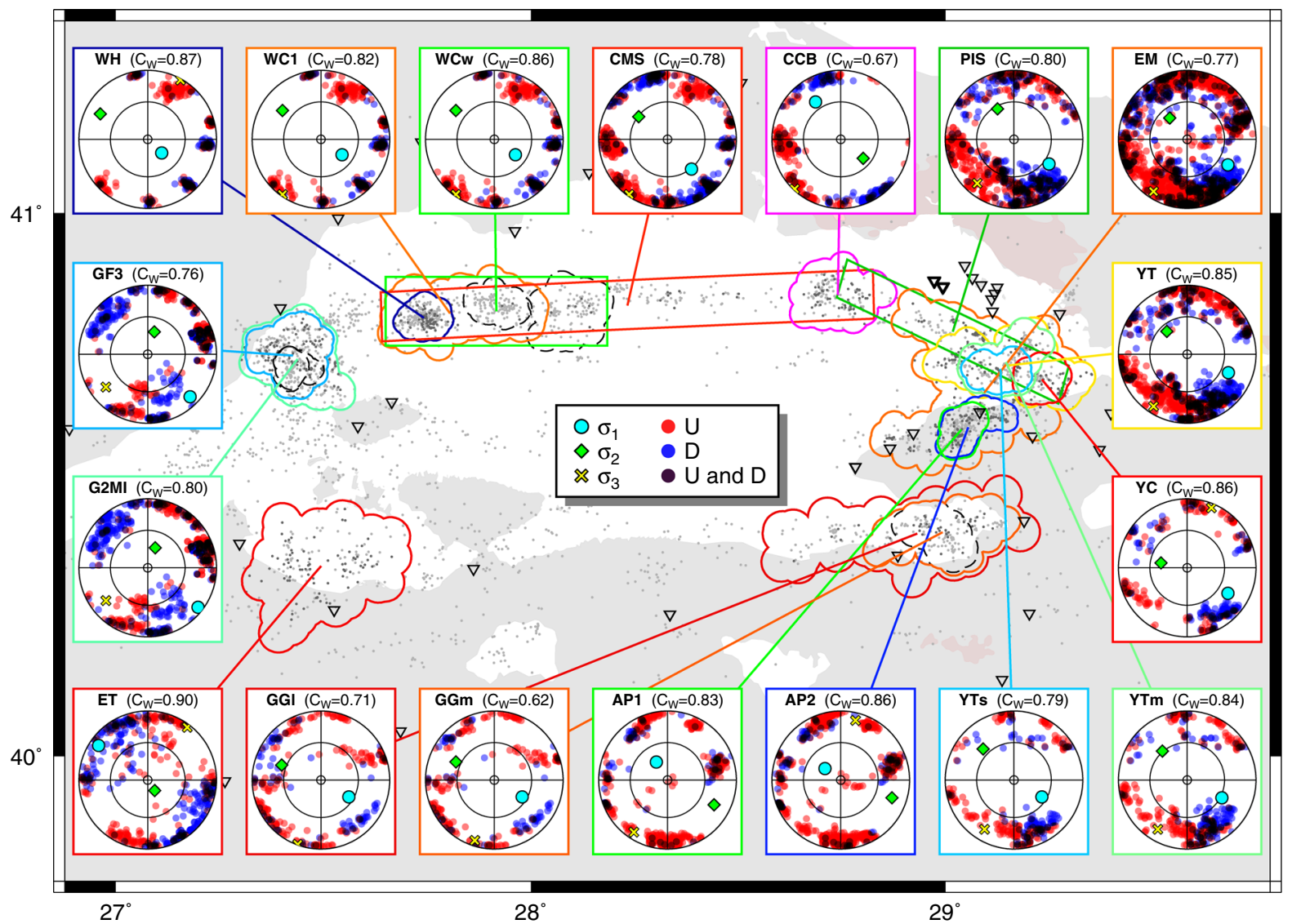

Figure 11

The insets show the measured first-motion distributions of local seismicity clusters in the Sea of Marmara. The clusters are delineated in the color of the insets' frame. The title of each inset indicates the abbreviation of the cluster name in bold letters (see Table 2) and the weighted cross-correlation coefficient with the corresponding synthetic first-motion distribution, $C_{\mathrm{W}}$

plunge, which supports our findings of it being weakly constrained not only due to a systematic observational gap, but also due to transtension.

\subsection{Stress Field in the Sea of Marmara}

We found a regionally consistent well-constrained SW-NE striking $\sigma_{3}$-axis for all local seismicity clusters in the study area. All deviations of $\sigma_{3}$-axis orientations lie within the uncertainties delineated by the boundary of the area of $68 \%$ confidence. This is in correspondence with a transtensional regional stress regime as indicated by the GPS-derived velocity field (Reilinger et al. 2006) and geological findings describing the Sea of Marmara region as a pull-apart structure (Armijo et al. 2005; Acarel et al. 2014).
Except for the westernmost areas of the region, the orientation of the $\sigma_{1}$-axis is consistent in its trend of about $\mathrm{N} 125^{\circ} \mathrm{E}$ but generally less well constrained in its plunge, the $95 \%$ confidence interval of its marginal PDF forming a great circle in the plane spanned with the $\sigma_{2}$-axis. This indicates that $\sigma_{1}$ and $\sigma_{2}$ do not differ substantially in their magnitudes. Unambiguous interpretation is aggravated by observational gaps in the first-motion distributions foremost preventing the numerical constrain of the shape ratio $R$, which is thus not further interpreted (also see Sect. 4.1).

However, we obtain a significant correlation between the measured and the corresponding synthetic first-motion distributions, $C_{\mathrm{W}}$ ranging between 0.62 and 0.91 , and we conclude that the first-motion 


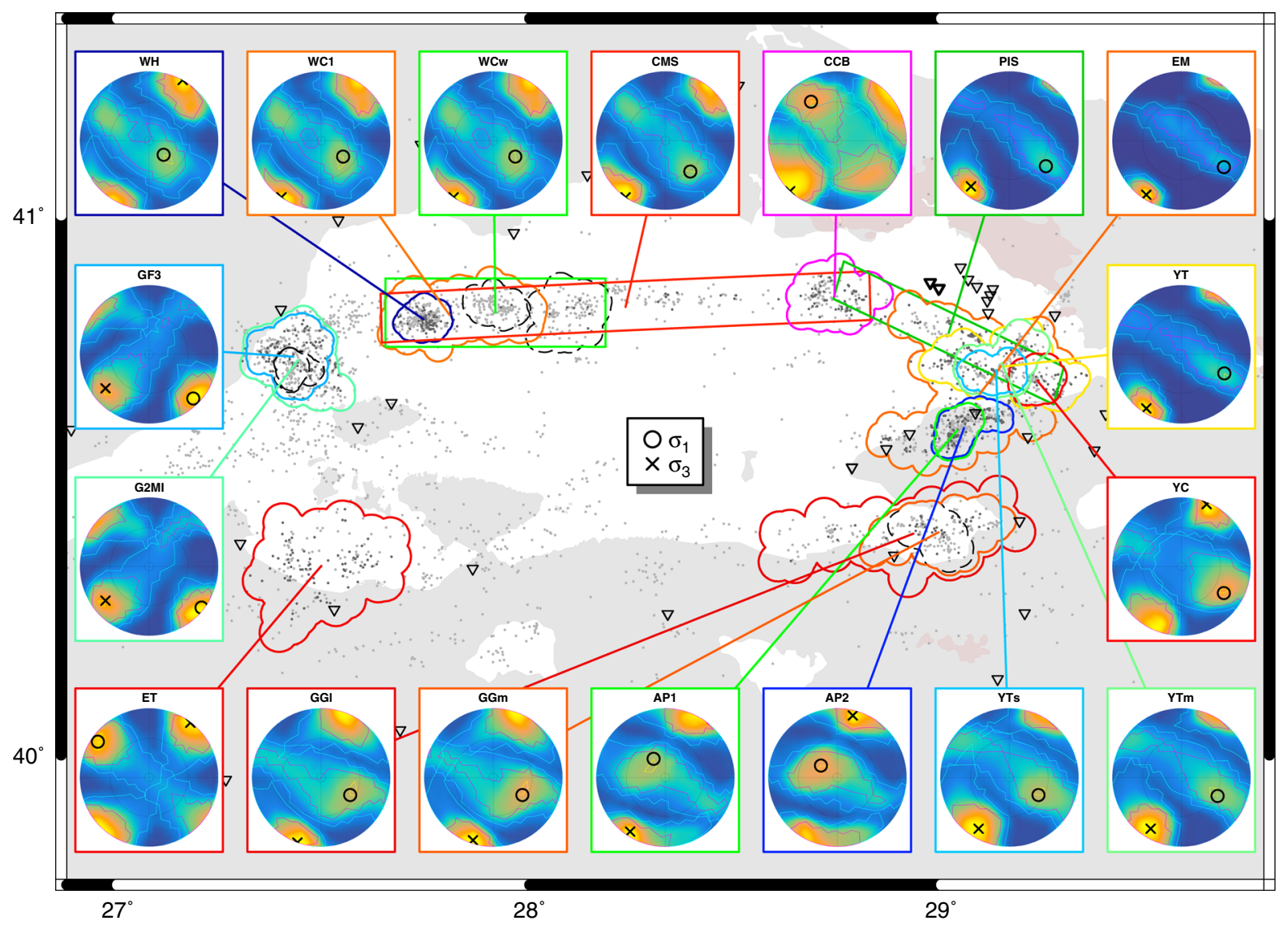

Figure 12

The insets show the combined marginal PDFs for the $\sigma_{1}$ - and $\sigma_{3}$-axis orientations as obtained from the stress inversion of local seismicity clusters in the Sea of Marmara. The frame of each inset is colored as the corresponding polygon delineating the seismicity used for an inversion. The corresponding first-motion distributions are shown in Fig. 11 and the numeric results are summarized in Table 2

measurements (1) were reliably determined, (2) fulfill the assumption of stress-field homogeneity to a large degree and (3) are representative for the calculated stress tensor within the areas of confidence. All measured first-motion distributions and the corresponding stress-inversion results are summarized in Figs. 11 and 12, respectively. Results for individual seismicity clusters are shown in Figs. 16-33 of Appendix 4 (Suplementary Material) and numeric results are listed in Table 2 where the inversions can be identified by the abbreviation of the seismicity clusters' name in bold letters. For each stress tensor, we also calculated the $95 \%$ confidence intervals of $S_{\text {Hmax }}$ following Lund and Townend (2007). The results are summarized in Fig. 13 where the different faulting regimes are categorized after Zoback (1992).

\subsubsection{Eastern Sea of Marmara Region}

Compared to the Princes' Islands Segment (PIS, dark green), the $\sigma_{1}$ - and $\sigma_{3}$-axis in the eastern Sea of Marmara between Yalova and Tuzla (YT, yellow) are slightly rotated counter-clockwise. This corresponds to the changing strike of the main fault branch further east, where it rotates from ESE-WNW to E-W. The Yalova-Tuzla cluster (YT, yellow) consists of several sub-clusters, of medium and small size (YTm and YTs), as well as a cluster at the coast of Yalova (YC). The stress-inversion results yield larger areas of $95 \%$ confidence for the principal stress axes $\left(A_{95 \%}\left(\sigma_{1}\right)\right.$ and $A_{95 \%}\left(\sigma_{3}\right)$ in Table 2), which is likely to stem from fewer observations per cluster. The results for these sub-clusters are congruent with those obtained for the parent and the Princes' Islands cluster (YT and PIS). 


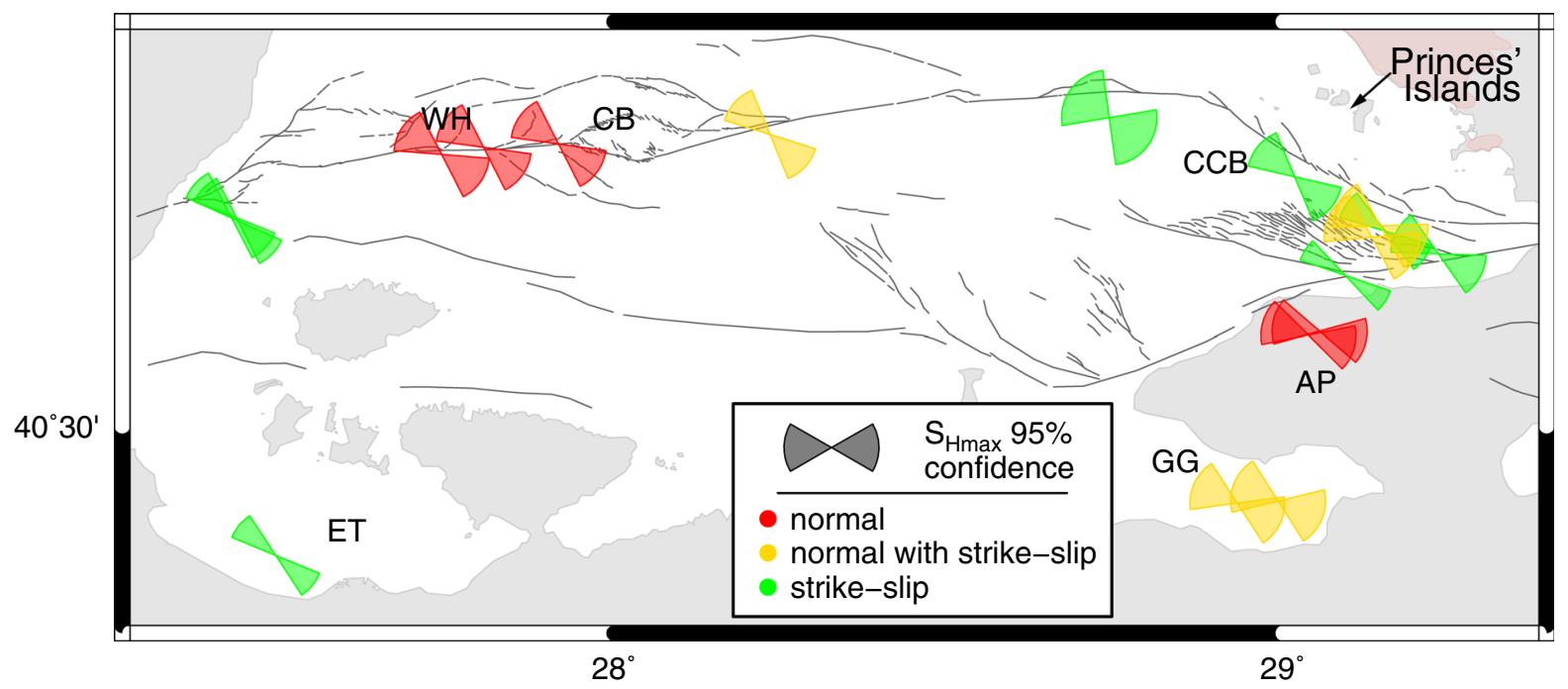

Figure 13

95\% confidence intervals of $S_{\mathrm{Hmax}}$ for all derived stress tensors. As in Fig. 12, the wedges are situated at the centroids of the corresponding clusters. Different faulting regimes are color coded and the regional abbreviations are as in Fig. 1

Stress tensors from seismicity clusters located on the Armutlu Pensinsula (AP1 and AP2) indicate a predominant normal faulting stress regime with strike-slip components. This is in agreement with earlier studies observing a substantial amount of normal faulting events (Örgülü 2011; Kinscher et al. 2013; Öztürk et al. 2015). However, a substantial number of positive first-motion polarities around the pole (Figs. 27a-28a in Appendix 4) indicate that this region shows a spatially heterogeneous tectonic setting observed also in focal mechanisms of the 1999 Izmit aftershocks (Bohnhoff et al. 2006). In general, the weighted cross-correlation between the distributions of observed and synthetic polarities yields a high similarity coefficient $\left(C_{\mathrm{W}}=0.86\right)$.

A joint inversion of the polarities from seismicity in the entire eastern Sea of Marmara (EM, orange) results in a stress tensor congruent with the results of the sub-clusters. The large number and the spread of seismicity over a large area leads to a dense first-motion distribution covering large parts of the focal sphere. Whilst the $\sigma_{3}$-axis orientation is the best resolved in the entire study, the confidence interval of the $\sigma_{1}$-axis delineates a ring-like area crossing the pole and striking ENE-WSW. Despite large uncertainties in the inversion results for the individual small sub-clusters, the results indicate the decomposition of the eastern Sea of Marmara into two stress regimes, one in the north tending towards strike-slip with a normal faulting component and one in the south tending towards normal faulting, respectively (Fig. 13). The orientations of the least compressive stress axes $\left(\sigma_{3}\right)$ are the same for both stress regimes.

The two seismicity clusters in the Gulf of Gemlik (GGm and GGl) south of the Armutlu Peninsula have comparatively fewer observations. The results for both marginal PDFs for the principal stress orientations are very similar and congruent with the values obtained for the offshore clusters north of the Armutlu Peninsula. The stress field orientation derived for the Gulf of Gemlik is dominantly NE-SW extensional strike-slip faulting with a significant normal component (Fig. 13). The extended confidence intervals show, however, a larger uncertainty. Still, the measured first-motion distribution is representative for the recovered stress field as it shows significant similarity with the corresponding synthetic first-motion distribution, i.e. $C_{\mathrm{W}}=0.62$ for the medium and even $C_{\mathrm{W}}=0.74$ for the larger cluster.

\subsubsection{Central Marmara Section}

The central Marmara Section is subject to large observational gaps. Hence, we can only perform 
stress inversions for three individual seismicity clusters. Two clusters are located in proximity to the Western High (WH and WC1), and the third cluster under the north-western part of the Cinarcik Basin at the Istanbul Bend (CCB). To resolve the local stress field orientation in the best possible way, we also invert polarities along two manually selected stripes along the central Marmara Section (WCw and CMS). The stress inversion for two seismicity clusters (two black-dashed polygons in Fig. 12) located at the edges of the Central Basin (CB in Fig. 1) were omitted due to lack of sufficient intermediate range first-motion observations. All first-motion distributions inverted here lack firstmotion observations with plunge larger than $45^{\circ}$ (Figs. 16a-20a in Appendix 4).

The resolved stress-field orientation along the central Marmara Section indicates a first-order NESW normal faulting stress regime with a wellconstrained $\sigma_{3}$-axis and a bimodal marginal PDF for the $\sigma_{1}$-axis where the two maxima approximately enclose an angle of $90^{\circ}$. No pure strike-slip component is observed while the oblique plunge of $\sigma_{1}$ indicates a dominantly normal faulting regime (Fig. 13). Below the northwestern part of the Cinarcik Basin at the Istanbul Bend the stress inversion displays large uncertainties. The maximum of the marginal PDF for the $\sigma_{3}$-axis orientation is in agreement with that of the neighboring central Marmara Section and the Princes Islands Segment. However, the $68 \%$ confidence area stretches over almost $40^{\circ}$. The marginal PDF of the $\sigma_{1}$-axis is bimodal indicating a trend of about $\mathrm{N} 125^{\circ} \mathrm{E}$. Although the measured and synthetic first-motion distributions display a significant similarity, the weighted cross-correlation coefficient $C_{\mathrm{W}}=0.67$ is low and comparable to the $C_{\mathrm{W}}$-values observed in the Gulf of Gemlik where the stress inversion was performed with only half as many first-motion observations. A possible explanation for the badly constrained stress field in the northwestern Cinarcik Basin is a prevalent stress heterogeneity at the Istanbul Bend where the fault trace changes strike abruptly and reverse faulting has been observed (Pinar et al. 2003).

\subsubsection{Western Sea of Marmara}

In the western Sea of Marmara, we performed stress inversions for: (1) a prominent offshore seismicity cluster at the eastern termination of the 1912 Ganosrupture, and (2) scattered seismic activity around the Erdek-Tombolo region (between GM and TB as well as ET in Fig. 1). In contrast to all other stress regimes presented in the eastern and central Marmara region, this area displays a clear predominant strike-slip stress field with thrust components. Further, the stress tensors retrieved for two seismicity clusters offshore the Ganos Mountains (GF3 is contained in G2MI, Fig. 12) show an elongated uncertainty of the $\sigma_{3}$-axis orientation which indicates a stress field with a transpressional component. While the obtained stress field clearly separates from all other areas of the region, it is in agreement with previous studies reporting transpression at this part of the Marmara Section (Armijo et al. 1999, 2002; Pinar et al. 2003; Janssen et al. 2009; Örgülü 2011). Generally, the distributions of measured and synthetic first motions show a high similarity with $C_{\mathrm{W}} \approx 0.78$ (Table 2), supporting the reliability of our results.

The stress regime in the Erdek Tombolo (GF3 is contained in G2MI) region along the southwestern shore of the Sea of Marmara is well resolved despite the fact that seismicity in this region is less spatially clustered than in all other regions considered here. This probably indicates a homogeneous stress field. The stress orientation is similar to that in the Tekirdak-Ganos region further to the north showing a predominant strike-slip stress regime. The 68\% confidence areas of both $\sigma_{1}$ - and $\sigma_{3}$-axis form circular regions.

\section{Conclusions}

We determine the stress field in the Sea of Marmara region along the main branch of the North Anatolian Fault Zone, where a major $(M>7)$ earthquake is pending in direct vicinity to the Istanbul population center. The stress field was calculated by inverting first-motion polarities of earthquakes reported in a recently published 10-year earthquake catalogue and we tested the reliability of our results 
by comparing measured and synthetic first-motion distributions.

Our results show a combined strike-slip and normal faulting regime reflecting the overall transtensional setting of the region. Whereas the orientation of the least compressive principal stress $\left(\sigma_{3}\right)$ is well resolved and almost constant throughout the region with an average trend of $\sim \mathrm{N} 35^{\circ} \mathrm{E}$ and a subhorizontal plunge, the largest $\left(\sigma_{1}\right)$ and intermediate $\left(\sigma_{2}\right)$ principal stresses show a similar trend of $\mathrm{N} 125^{\circ} \mathrm{E}$ on average but locally varying plunges. Local variations of the stress field orientation are found throughout the region. Synthetic tests show that the shape ratio $\mathrm{R}$ (also called the relative stress magnitude) cannot be well constrained. However, a transtensional stress regime might be indicated by observations of elongated confidence intervals of the $\sigma_{1}$ - and $\sigma_{2}$-axis.

In the eastern Sea of Marmara, the Armutlu Peninsula displays a normal faulting regime. To its north and south, around the Princes' Islands Segment and the Gulf of Gemlik, strike-slip regimes with minor or more pronounced normal faulting components prevail. Along the central Marmara Section, normal faulting tends to dominate while a strike-slip stress regime is found in the western Sea of Marmara region. Regarding the pending major Marmara earthquake, the results indicate that neither a pure strike-slip nor a pure normal faulting mechanism is to be expected. Rather, a combination of both faulting styles needs to be considered with implications to local hazard and subsequent risk. It is conceivable that several en-echelon normal faulting earthquakes in contrast to an earthquake with a significant strikeslip component, would expose the near coastal areas to a tsunami and areas further inland to substantial ground motions, respectively. Our results could be used to calculate the traction of individual faults whose strike and dip are known, to further constrain their potential faulting style.

\section{Acknowledgements}

We acknowledge funding from the Helmholtz Association in the frame of the Young Investigators Group SO-053 and Helmholtz Postdoc Programme, and from the German Research Foundation DFG under Grant Bo1877/6. The work was partially supported by the Grant Agency of the Czech Republic, Grant 16-19751J. The maps and lower hemisphere projections were plotted with the Generic Mapping Tool (GMT) (Wessel et al. 2013). The automatic picker was implemented with MATLAB ${ }^{\circledR}$. We thank two anonymous reviewers for their constructive remarks that substantially improved our manuscript.

Open Access This article is distributed under the terms of the Creative Commons Attribution 4.0 International License (http:// creativecommons.org/licenses/by/4.0/), which permits unrestricted use, distribution, and reproduction in any medium, provided you give appropriate credit to the original author(s) and the source, provide a link to the Creative Commons license, and indicate if changes were made.

\section{Appendix 1: Density-Based Clustering}

Given a set of elements for which a metric is defined, Density-based spatial clustering of applications with noise (DBSCAN) (Ester et al. 1996) uses two parameters, (1) $N_{\mathrm{c}}$, the minimum number of elements, and (2) $r_{\mathrm{c}}$, the maximum distance between elements, to define a cluster-density and to group the set of elements. DBSCAN categorizes the set of elements into three groups: (1) core-points define a cluster of elements where the sets of core-points of different clusters are disjunct; (2) border-points may belong to several clusters and (3) noise are outliers that are not associable to any cluster. The algorithm is deterministic regarding the separation of core-points and a boundary including core- and border-points may be defined by the union of the $r_{c}$ neighborhoods of the core-points. We "blew up" the set of events associated to a cluster by calculating the union of $r_{\mathrm{c}}+r_{\mathrm{b}}$ neighborhoods of its core- and border-points. We added all events within this boundary to a cluster, condoning the intersection of clusters. An example of how these three parameters may define clusters of different size and density is given in Fig. 14 for four sets of $N_{\mathrm{c}}, r_{\mathrm{c}}$ and $r_{\mathrm{b}}$ (the parameters used in this study are summarized in Table 1). Despite being calculated with different sets of parameters, some of the "blown up" clusters consist of almost the same subset of earthquakes. We define the similarity of two subsets 


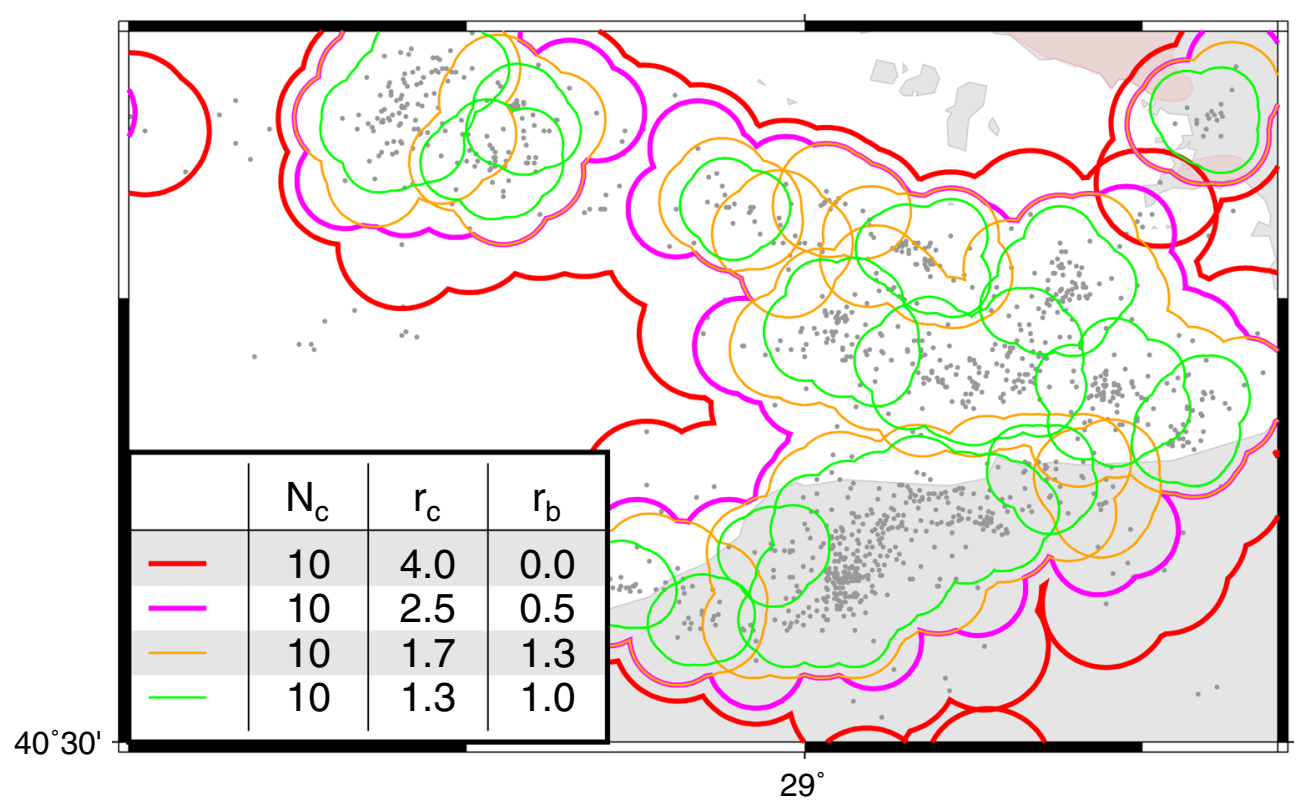

Figure 14

Results of density-based clustering (DBSCAN) applied to the seismicity in the eastern Sea of Marmara with four different sets of parameters $N_{\mathrm{c}}, r_{\mathrm{c}}$ and $r_{\mathrm{b}}$ emphasizing clusters of increasing density. $N_{\mathrm{c}}$ is the minimum number of earthquakes within an epicentral distance $r_{\mathrm{c}}$, and $r_{\mathrm{b}}$ is an additional radius that defines the cluster boundary

as the fraction of the number of earthquakes in their intersection over those in their union. If this fraction is larger than 0.9 , the two subsets are considered similar and only the larger one is kept as a representative.

\section{Appendix 2: Synthetic First-Motion Polarity Distributions}

We apply the theory on the mechanics of faulting as presented in Vavryčuk $(2011,2015)$ (see also Martínez-Garzón et al. 2016b) to derive distributions of first-motion polarities on the focal sphere from stress field parameters.

Given the orientation and shape ratio of the principal stresses, the shear and normal stresses acting on an arbitrary plane are functions of its orientation. In the Mohr-Circle diagram, every pair of shear and normal stress represents a possible fault orientation. For activated faults, the shear stress should exceed the critical threshold $t_{c}$ given by the Mohr-Coulomb failure-criterion

$$
t_{c}=C+\mu\left(\sigma_{n}-p\right),
$$

where $\sigma_{n}$ denotes the normal stress, i.e. the normal component of the traction $\boldsymbol{t}$. Here compressional stress has positive sign (convention in rock mechanics Shearer 1999; Zoback 2007) and the parameters in this equation are dimensionless, because we normalize the stress tensor by fixing the stress magnitudes to the values $\sigma_{1}=2$ and $\sigma_{3}=0$ (e.g. Vavryčuk 2015; Martínez-Garzón et al. 2016b). The friction $\mu=0.6$ is chosen to reflect commonly accepted values (Zoback 2007; Byerlee 1978; Vavryčuk 2015; Martínez-Garzón et al. 2016b) and the cohesion $C=0.2$ and the pore pressure $p=0.5$ are adapted such that the Mohr-Coulomb failure-criterion well penetrates into the outer Mohr-Circle of normalized stress magnitudes. The slip vector is parallel to the shear stress and together with the fault normal constrains a focal mechanism. The first-motion polarity of a P-wave along some ray $\boldsymbol{x}$ was then calculated after Shearer (1999),

$$
f(\boldsymbol{x})=\operatorname{sign}(\boldsymbol{x} \cdot \dot{\boldsymbol{M}} \cdot \boldsymbol{x}),
$$



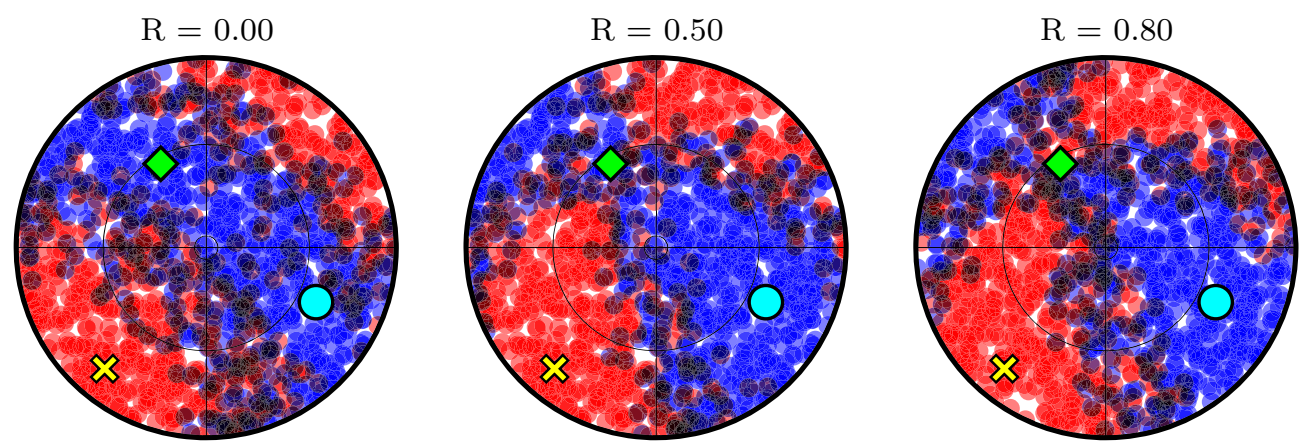

Figure 15

Synthetic first-motion distributions for three different shape ratios (Eq. 1). Symbols are as in Fig. 5

where $\dot{\boldsymbol{M}}$ is the time derivative of the moment tensor and $f= \pm 1$ is equivalent to an up and down first motion, respectively.

Figure 15 shows three exemplary synthetic firstmotion distributions calculated for the same stressaxis orientations but for three different values of the shape ratio $R$ (Eq. 1) where the first motions were evaluated along uniformly distributed rays. The distribution for $R=0$ is rotationally symetric around the $\sigma_{3}$ axis (yellow 'x') and represents a pure transtensional stress regime. With increasing $R$ the neighborhood of the $\sigma_{2}$-axis is increasingly populated with positive first motions until, towards a transpressional stress regime at $R=0.8$, they begin to dominate there. At $R=1.0$, the rotational symmetry would be established around the $\sigma_{1}$-axis.

\section{Appendix 3: Weighted Cross-Correlation of First- Motion Distributions}

Let us consider a circular patch $P$ of the focal sphere which is centered around the piercing point of some unit vector $\boldsymbol{r}$. We then search the rays with an up polarity piercing the focal sphere within this patch and define their total number as $N_{\mathrm{u}}(P)$. Accordingly, the number of down first motions piercing the focal sphere through the patch $P$ is given by $N_{\mathrm{d}}(P)$. The difference of fractions of first-motion polarities within $P$ is then given by

$$
\varrho(P)=\frac{N_{\mathrm{u}}(P)-N_{\mathrm{d}}(P)}{N_{\mathrm{u}}(P)+N_{\mathrm{d}}(P)},
$$

which is not defined for patches without any piercing rays. If the nonempty patch $P$ contains, for instance,

1. only up-polarites, i.e. $N_{\mathrm{d}}(P)=0$, then $\varrho(P)=1$,

2. only down-polarites, i.e. $N_{\mathrm{u}}(P)=0$, then $\varrho(P)=-1$,

3. as many up- as down-polarities, then $\varrho(P)=0$.

For a set of $M$ equally sized, non-overlapping and non-empty patches $P_{m}$, i.e. patches pierced by at least one ray, where $m=1, \ldots, M$, we obtain a vector of differences of fractions

$$
\varrho=\left(\varrho_{1}, \ldots, \varrho_{M}\right) .
$$

The weighted cross-correlation coefficient between two first-motion distributions represented by the vectors $\varrho_{1}$ and $\varrho_{2}$ finally reads

$$
C_{\mathrm{W}}\left(\varrho_{1}, \varrho_{2}\right)=\frac{\sum_{m=1}^{M} \varrho_{1 m} \cdot \varrho_{2 m} \cdot N\left(P_{m}\right)}{\sqrt{\sum_{m=1}^{M} \varrho_{1 m}{ }^{2} \cdot N\left(P_{m}\right)} \sqrt{\sum_{m=1}^{M} \varrho_{2 m}{ }^{2} \cdot N\left(P_{m}\right)}},
$$

where $N\left(P_{m}\right)=N_{u}(P)+N_{d}(P)$ represent the total number of first-motion polarities (up or down) measured within the $m$ th patch $P_{m}$ such that their sum $\sum_{m=1}^{M} N\left(P_{m}\right)$ equals the total number of rays or polarities constituting a first-motion distribution. $C_{\mathrm{W}}$ thus emphasizes patches containing many rays for which a better estimate of the difference of fractions of up and down first motions $\varrho_{m}$ can be assumed. 


\section{Appendix 4: Stress-Tensor Inversion Results for Local Seismicity Clusters}

See Supplementary Material.

\section{REFERENCES}

Abers, G. A., \& Gephart, J. W. (2001). Direct inversion of earthquake first motions for both the stress tensor and focal mechanisms and application to Southern California. Journal of Geophysical Research Solid Earth, 106(B11), 26523-26540. https://doi.org/10.1029/2001JB000437 (ISSN 2156-2202).

Acarel, D., Bulut, F., Bohnhoff, M., \& Kartal, R. (2014). Coseismic velocity change associated with the 2011 Van Earthquake (M7.1): Crustal response to a major event. Geophysical Research Letters, 41(13), 4519-4526. https://doi.org/10.1002/ 2014GL060624(ISSN 1944-8007).

Ambraseys, N. N. (1970). Some characteristic features of the Anatolian fault zone. Tectonophysics, 9(2-3), 143-165. https:// doi.org/10.1016/0040-1951(70)90014-4(ISSN 0040-1951).

Armijo, R., Meyer, B., Hubert, A., \& Barka, A. (1999). Westward propagation of the North Anatolian fault into the northern Aegean: Timing and kinematics. Geology, 27(3), 267-270.

Armijo, R., Meyer, B., Navarro, S., King, G., \& Barka, A. (2002). Asymmetric slip partitioning in the Sea of Marmara pull-apart: A clue to propagation processes of the North Anatolian Fault? Terra Nova, 14(2), 80-86. https://doi.org/10.1046/j.1365-3121. 2002.00397.x(ISSN 1365-3121).

Armijo, R., Pondard, N., Meyer, B., Uçarkus, G., de Lépinay, B. M., Malavieille, J., et al. (2005). Submarine fault scarps in the sea of Marmara Pull-Apart (North Anatolian Fault): Implications for seismic hazard in Istanbul. Geochemistry Geophysics Geosystems, 6, 6. https://doi.org/10.1029/2004GC000896(ISSN 1525-2027).

Bąs, M., \& Yăgci, M. (2008). Disaster prevention mitigation studies for a safer urban life measures for preventing disaster of Istanbul Metropolitan Municipality. In Megacity Istanbul Megacity Project Reports. Istanbul, Turkey: Municipality Disaster Management Center (AKOM). http://www.cedim.de/ download/Megacity_Istanbul_Final_Report2008.pdf.

Barka, A. (1992). The north Anatolian fault zone. Annales Tectonicae, 6, 164-195.

Barka, A., Akyüz, H. S., Altunel, E., Sunal, G., Çakir, Z., \& Dikbas, A. (2002). The surface rupture and slip distribution of the 17 August 1999 İzmit Earthquake (M 7.4), North Anatolian Fault. Bulletin of the Seismological Society of America, 92(1), 43. https://doi.org/10.1785/0120000841.

Bécel, A., Laigle, M., de Voogd, B., Hirn, A., Taymaz, T., \& Galvé, A. (2009). Moho, crustal architecture and deep deformation under the North Marmara Trough, from the SEISMARMARA Leg 1 offshore-onshore reflection-refraction survey. Tectonophysics, 467(1-4), 1-21. https://doi.org/10.1016/ j.tecto.2008.10.022. (ISSN 0040-1951).

Bohnhoff, M., Baisch, S., \& Harjes, H.-P. (2004). Fault mechanisms of induced seismicity at the superdeep German Continental Deep Drilling Program (KTB) borehole and their relation to fault structure and stress field. Journal of Geophysical Research Solid
Earth, 109, B2. https://doi.org/10.1029/2003JB002528(ISSN 2156-2202).

Bohnhoff, M., Harjes, H.-P., \& Meier, T. (2005). Deformation and stress regimes in the Hellenic subduction zone from focal Mechanisms. Journal of Seismology, 9(3), 341-366. https://doi. org/10.1007/s10950-005-8720-5(ISSN 1573-157X).

Bohnhoff, M., Grosser, H., \& Dresen, G. (2006). Strain partitioning and stress rotation at the North Anatolian fault zone from aftershock focal mechanisms of the 1999 Izmit $\mathrm{Mw}=7.4$ earthquake. Geophysical Journal International, 166(1), 373-385. https://doi.org/10.1111/j.1365-246X.2006.03027.x.

Bohnhoff, M., Bulut, F., Dresen, G., Malin, P. E., Eken, T., \& Aktar, M. (2013). An earthquake gap south of Istanbul. Nature Communications,. https://doi.org/10.1038/ncomms2999.

Bohnhoff, M., Ickrath, M., \& Dresen, G. (2016a). Seismicity distribution in conjunction with spatiotemporal variations of coseismic slip and postseismic creep along the combined 1999 Izmit-Düzce rupture. Tectonophysics, 686, 132-145. https://doi. org/10.1016/j.tecto.2016.07.029.

Bohnhoff, M., Martínez-Garzón, P., Bulut, F., Stierle, E., \& BenZion, Y. (2016b). Maximum earthquake magnitudes along different sections of the North Anatolian fault zone. Tectonophysics, 674, 147-165. https://doi.org/10.1016/j.tecto.2016.02.028(ISSN 0040-1951).

Bohnhoff, M., Dresen, G., Ceken, U., Kadirioglu, F. T., Kartal, R. F., \& Kilic, T. (2017). GONAF-the borehole geophysical observatory at the North Anatolian Fault in the eastern Sea of Marmara. Scientific Drilling, 22, 19-28. https://doi.org/10.5194/ sd-22-19-2017.

Bohnhoff, M., Wollin, C., Domigall, D., Küperkoch, L., MartínezGarzón, P., Kwiatek, G., et al. (2017b). Repeating Marmara Sea earthquakes: Indication for fault creep. Geophysical Journal International, 210(1), 332-339. https://doi.org/10.1093/gji/ggx169.

Bott, M. H. P. (1959). The mechanics of oblique slip faulting. Geological Magazine, 96(2):109-117. http://geolmag. geoscienceworld.org/content/96/2/109(ISSN 0016-7568).

Bulut, F., \& Aktar, M. (2007). Accurate relocation of İzmit Earthquake $(\mathrm{Mw}=7.4,1999)$ Aftershocks in Çınarcık Basin using double difference method. Geophysical Research Letters, 34(10), 2007. https://doi.org/10.1029/2007GL029611.

Bulut, F., Bohnhoff, M., Aktar, M., \& Dresen, G. (2007). Characterization of aftershock-fault plane orientations of the 1999 İzmit (Turkey) earthquake using high-resolution aftershock locations. Geophysical Research Letters, 34, 20. https://doi.org/ 10.1029/2007GL031154(ISSN 1944-8007).

Bulut, F., Bohnhoff, M., Eken, T., Janssen, C., Kılıç, T., \& Dresen, G. (2012). The East Anatolian Fault Zone: Seismotectonic setting and spatiotemporal characteristics of seismicity based on precise earthquake locations. Journal of Geophysical Research Solid Earth, 117, B7. https://doi.org/10.1029/2011JB008966(ISSN 2156-2202).

Byerlee, J. (1978). Friction of rocks. Pure and Applied Geophysics, 116(4), 615-626. https://doi.org/10.1007/BF00876528(ISSN 1420-9136).

Eken, T., Bohnhoff, M., Bulut, F., Can, B., \& Aktar, M. (2013). Crustal anisotropy in the eastern sea of Marmara Region in Northwestern Turkey. Bulletin of the Seismological Society of America, 103(2A), 911-924. https://doi.org/10.1785/ 0120120156(ISSN 0037-1106).

Ergintav, S., Reilinger, R. E., Çakmak, R., Floyd, M., Cakir, Z., Doğan, U., et al. (2014). Istanbul's earthquake hot spots: 
Geodetic constraints on strain accumulation along faults in the Marmara Seismic Gap. Geophysical Research Letters, 41(16), 5783-5788. https://doi.org/10.1002/2014GL060985(ISSN 1944-8007).

Ester, M., Kriegel, H.-P., Sander, J., \& Xu, X. (1996). A densitybased algorithm for discovering clusters in large spatial databases with noise. In Proceedings of the Second International Conference on Knowledge Discovery and Data Mining, KDD'96 (pp. 226-231). New York: AAAI Press.

Flerit, F., Armijo, R., King, G., \& Meyer, B. (2004). The mechanical interaction between the propagating North Anatolian Fault and the back-arc extension in the Aegean. Earth and Planetary Science Letters, 224(3), 347-362. https://doi.org/10. 1016/j.eps1.2004.05.028(ISSN 0012-821X).

Han, J., Pei, J., \& Kamber, M. (2011). Data mining: Concepts and techniques. In The Morgan Kaufmann series in data management systems. Oxford: Elsevier Science.

Hardebeck, J. L., \& Hauksson, E. (1999). Role of fluids in faulting inferred from stress field signatures. Science, 285(5425), 236-239. https://doi.org/10.1126/science.285.5425.236(ISSN 0036-8075).

Hardebeck, J. L., \& Michael, A. J. (2006). Damped regional-scale stress inversions: Methodology and examples for southern California and the Coalinga aftershock sequence. Journal of Geophysical Research Solid Earth, 111, B11. https://doi.org/10. 1029/2005JB004144(ISSN 2156-2202).

Hardebeck, J. L., \& Okada, T. (2018). Temporal stress changes caused by earthquakes: A review. Journal of Geophysical Research Solid Earth, $\quad$ https://doi.org/10.1002/ 2017JB014617(ISSN 2169-9356).

Hébert, H., Schindelé, F., Altinok, Y., Alpar, B., \& Gazioglu, C. (2005). Tsunami Hazard in the Marmara Sea (Turkey): A numerical approach to discuss active faulting and impact on the Istanbul Coastal Areas. Tsunamis in the Pacific, in the Atlantic and in Europe: relevant cases and hazard evaluation. Marine Geology, 215(1), 23-43. https://doi.org/10.1016/j.margeo.2004. 11.006(ISSN 0025-3227).

Hergert, T., \& Heidbach, O. (2010). Slip-rate variability and distributed deformation in the Marmara Sea fault system. Nature Geoscience, 3(2), 132-135.

Hergert, T., Heidbach, O., Bécel, A., \& Laigle, M. (2011). Geomechanical model of the Marmara Sea Region-I. 3-D contemporary kinematics. Geophysical Journal International, 185(3), 1073-1089. https://doi.org/10.1111/j.1365-246X.2011.04991.x.

Ickrath, M., Bohnhoff, M., Dresen, G., Martínez-Garzón, P., Bulut, F., \& Kwiatek, G. (2015). Detailed analysis of spatiotemporal variations of the stress field orientation along the Izmit-Düzce rupture in NW Turkey from inversion of first-motion polarity data. Geophysical Journal International, 202(3), 2120-2120. https://doi.org/10.1093/gji/ggv273.

Janssen, C., Bohnhoff, M., Vapnik, Y., Görgün, E., Bulut, F., Plessen, B., et al. (2009). Tectonic evolution of the Ganos segment of the North Anatolian Fault (NW Turkey). Journal of Structural Geology, 31(1), 11-28. https://doi.org/10.1016/j.jsg. 2008.09.010(ISSN 0191-8141).

Karabulut, H., Bouin, M.-P., Bouchon, M., Dietrich, M., Cornou, C., \& Aktar, M. (2002). The seismicity in the Eastern Marmara Sea after the 17 August 1999 İzmit earthquake. Bulletin of the Seismological Society of America, 92(1), 387-393. https://doi. org/10.1785/0120000820(ISSN 0037-1106).
Karabulut, H., Schmittbuhl, J., Özalaybey, S., Lengliné, O., Kömeç-Mutlu, A., Durand, V., et al. (2011). Evolution of the seismicity in the eastern Marmara Sea a decade before and after the 17 August 1999 Izmit earthquake. Tectonophysics, 510(1-2), 17-27. https://doi.org/10.1016/j.tecto.2011.07.009(ISSN 0040-1951).

Ketin, I. (1948). Über die tektonisch-mechanischen Folgerungen aus den großen anatolischen Erdbeben des letzten Dezenniums. Geologische Rundschau, 36(1), 77-83. https://doi.org/10.1007/ BF01791916(ISSN 1432-1149).

Kinscher, J., Krüger, F., Woith, H., Lühr, B., Hintersberger, E., \& Irmak, T. (2013). Seismotectonics of the Armutlu Peninsula (Marmara Sea, NW Turkey) from geological field observation and regional moment tensor inversion. Tectonophysics, 608, 980-995. https://doi.org/10.1016/j.tecto.2013.07.016.

Kiratzi, A. A. (2002). Stress tensor inversions along the westernmost North Anatolian Fault Zone and its continuation into the North Aegean Sea. Geophysical Journal International, 151(2), 360-376. https://doi.org/10.1046/j.1365-246X.2002.01753.x.

Latcharote, P., Suppasri, A., Imamura, F., Aytore, B., \& Yalciner, A. C. (2016). Possible worst-case tsunami scenarios around the Marmara Sea from combined earthquake and landslide sources. Pure and Applied Geophysics, 173(12), 3823-3846. https://doi. org/10.1007/s00024-016-1411-z(ISSN 1420-9136).

Le Pichon, X., Şengör, A., \& Taymaz, T. (1999). The Marmara fault and the future Istanbul earthquake (pp. 41-54). Istanbul: Istanbul Technical University.

Le Pichon, X., Şengör, A., Demirbăg, E., Rangin, C., Imren, C., Armijo, R., et al. (2001). The active Main Marmara Fault. Earth and Planetary Science Letters, 192(4), 595-616. https://doi.org/ 10.1016/S0012-821X(01)00449-6(ISSN 0012-821X).

Le Pichon, X., İmren, C., Rangin, C., Şengör, A., \& Siyako, M. (2014). The South Marmara Fault. International Journal of Earth Sciences, 103(1), 219-231. https://doi.org/10.1007/s00531-0130950-0(ISSN 1437-3254).

Le Pichon, X., Şengör, A., Kende, J., İmren, C., Henry, P., Grall, C., et al. (2015). Propagation of a strike slip plate boundary within an extensional environment: The westward propagation of the North Anatolian Fault. Canadian Journal of Earth Sciences,. https://doi.org/10.1139/cjes-2015-0129.

Lund, B., \& Townend, J. (2007). Calculating horizontal stress orientations with full or partial knowledge of the tectonic stress tensor. Geophysical Journal International, 170(3), 1328-1335. https://doi.org/10.1111/j.1365-246X.2007.03468.x.

Martínez-Garzón, P., Bohnhoff, M., Kwiatek, G., \& Dresen, G. (2013). Stress tensor changes related to fluid injection at The Geysers geothermal field. California. Geophysical Research Letters, 40(11), 2596-2601. https://doi.org/10.1002/grl. 50438(ISSN 1944-8007).

Martínez-Garzón, P., Ben-Zion, Y., Abolfathian, N., Kwiatek, G.,\& Bohnhoff, M. (2016a). A refined methodology for stress inversions of earthquake focal mechanisms: Refined stress inversion methodology. Journal of Geophysical Research Solid Earth.

Martínez-Garzón, P., Vavryčuk, V., Kwiatek, G., \& Bohnhoff, M. (2016b). Sensitivity of stress inversion of focal mechanisms to pore pressure changes. Geophysical Research Letters, 43(16), 8441-8450. https://doi.org/10.1002/2016GL070145(ISSN 1944-8007)(ISSN 1944-8007).

McClusky, S., Balassanian, S., Barka, A., Demir, C., Ergintav, S., Georgiev, I., et al. (2000). Global positioning system constraints 
on plate kinematics and dynamics in the eastern Mediterranean and Caucasus. Journal of Geophysical Research: Solid Earth, 105(B3), 5695-5719. https://doi.org/10.1029/ 1999JB900351(ISSN 2156-2202).

McKenzie, D. P. (1969). The relation between fault plane solutions for earthquakes and the directions of the principal stresses. Bulletin of the Seismological Society of America, 59(2):591-601. http://bssa.geoscienceworld.org/content/59/2/591(ISSN 0037-1106)

Murru, M., Akinci, A., Falcone, G., Pucci, S., Console, R., \& Parsons, T. (2016). $M \geq 7$ earthquake rupture forecast and timedependent probability for the sea of Marmara region, Turkey. Journal of Geophysical Research Solid Earth, 121(4), 2679-2707. https://doi.org/10.1002/2015JB012595(ISSN 2169-9356).

Najdahmadi, B., Bohnhoff, M., \& Ben-Zion, Y. (2016). Bimaterial interfaces at the Karadere segment of the North Anatolian Fault, Northwestern Turkey. Journal of Geophysical Research Solid Earth, 121(2), 931-950. https://doi.org/10.1002/ 2015JB012601(ISSN 2169-9356).

Najdahmadi, B., Hrubcová, P., Vavryčuk, V., \& Bohnhoff, M. (2018). Imaging the Mudurnu segment of the North Anatolian fault zone from waveforms of small earthquakes. Journal of Geophysical Research Solid Earth, 123(1), 493-512. https://doi. org/10.1002/2017JB015198.

Örgülü, G. (2011). Seismicity and source parameters for smallscale earthquakes along the splays of the North Anatolian Fault (NAF) in the Marmara Sea. Geophysical Journal International, 184(1), 385-404. https://doi.org/10.1111/j.1365-246X.2010. 04844.X.

Öztürk, Y. K., Özal, N. M., \& Özbakir, A. D. (2015). States of local stresses in the Sea of Marmara through the analysis of large numbers of small earthquakes. Tectonophysics, 665, 37-57. https://doi.org/10.1016/j.tecto.2015.09.027(ISSN 0040-1951).

Parsons, T. (2004). Recalculated probability of M7 earthquakes beneath the Sea of Marmara, Turkey. Journal of Geophysical Research Solid Earth, 109, B5. https://doi.org/10.1029/ 2003JB002667(ISSN 2156-2202).

Pinar, A., Honkura, Y., \& Kuge, K. (2001). Seismic activity triggered by the 1999 Izmit earthquake and its implications for the assessment of future seismic risk. Geophysical Journal International, 146(1), F1-F7. https://doi.org/10.1046/j.0956-540x.2001. 01476.x(ISSN 1365-246X).

Pinar, A., Kuge, K., \& Honkura, Y. (2003). Moment tensor inversion of recent small to moderate sized earthquakes: Implications for seismic hazard and active tectonics beneath the Sea of Marmara. Geophysical Journal International, 153(1), 133-145. https://doi.org/10.1046/j.1365-246X.2003.01897.x.

Reilinger, R., McClusky, S., Vernant, P., Lawrence, S., Ergintav, S., Cakmak, R., et al. (2006). GPS constraints on continental deformation in the Africa-Arabia-Eurasia continental collision zone and implications for the dynamics of plate interactions. Journal of Geophysical Research Solid Earth, 111, B5a. https:// doi.org/10.1029/2005JB004051(ISSN 2156-2202).
Robinson, R., \& McGinty, P. J. (2000). The enigma of the Arthur's Pass, New Zealand, earthquake: 2. The aftershock distribution and its relation to regional and induced stress fields. Journal of Geophysical Research: Solid Earth, 105(B7), 16139-16150. https://doi.org/10.1029/2000JB900012 (ISSN 2156-2202).

Şengör, A. C., Tüysüz, O., İmren, C., Sakınç, M., Eyidoğan, H., \& Görür, N. (2005). The North Anatolian fault: A new look. Annual Review of Earth and Planetary Sciences, 33(1), 37-112. https:// doi.org/10.1146/annurev.earth.32.101802.120415.

Şengör, A. C., Grall, C., İmren, C., Le Pichon, X., Görür, N., Henry, P., et al. (2014). The geometry of the North Anatolian transform fault in the Sea of Marmara and its temporal evolution: Implications for the development of intracontinental transform faults. Canadian Journal of Earth Sciences, 51(3), 222-242. https://doi.org/10.1139/cjes-2013-0160(ISSN 0008-4077).

Shearer, P. M. (1999). Introduction to seismology. Cambridge: Cambridge University Press.

Tibi, R., Bock, G., Xia, Y., Baumbach, M., Grosser, H., \& Milkereit, C. (2001). Rupture processes of the 1999 August 17 Izmit and November 12 Düzce (Turkey) earthquakes. Geophysical Journal International, 144(2), F1-F7. https://doi.org/10.1046/j. 1365-246x.2001.00360.x. (ISSN 1365-246X).

Townend, J., \& Zoback, M. D. (2001). Implications of earthquake focal mechanisms for the frictional strength of the San Andreas fault system. Geological Society London Special Publications, 186(1), 13-21. https://doi.org/10.1144/GSL.SP.2001.186.01. 02(ISSN 0305-8719).

Vavryčuk, V. (2014). Iterative joint inversion for stress and fault orientations from focal mechanisms. Geophysical Journal International, 199(1), 69-77. https://doi.org/10.1093/gji/ggu224.

Vavryčuk, V. (2011). Principal earthquakes: Theory and observations from the 2008 West Bohemia swarm. Earth and Planetary Science Letters, 305(3), 290-296. https://doi.org/10.1016/j.epsl. 2011.03.002(ISSN 0012-821X).

Vavryčuk, V. (2015). Earthquake mechanisms and stress field. In M. Beer, I. A. Kougioumtzoglou, E. Patelli, \& S.-K. Au (Eds.), Encyclopedia of earthquake engineering (pp. 728-746). Berlin: Springer. https://doi.org/10.1007/978-3-642-36197-5_295-1 (ISBN 978-3-642-35344-4).

Wallace, R. E. (1951). Geometry of shearing stress and relation to faulting. The Journal of Geology, 59(2), 118-130. https://doi.org/ $10.1086 / 625831$.

Wessel, P., Smith, W. H. F., Scharroo, R., Luis, J., \& Wobbe, F. (2013). Generic mapping tools: Improved version released. Eos, Transactions American Geophysical Union, 94(45), 409-410. https://doi.org/10.1002/2013EO450001(ISSN 2324-9250).

Wollin, C., Bohnhoff, M., Martínez-Garzón, P., Küperkoch, L., \& Raub, C., (2018). A unified earthquake catalogue for the Sea of Marmara Region, Turkey, based on automatized phase picking and travel-time inversion: Seismotectonic implications. Tectonophysics, $\quad$ https://doi.org/10.1016/j.tecto.2018.05.020 (ISSN 0040-1951).

Yalçıner, A. C., Alpar, B., Altınok, Y., Özbay, İ., \& Imamura, F. (2002). Tsunamis in the Sea of Marmara: Historical documents 
for the past. Models for the future. Marine Geology, 190(1), 445-463. https://doi.org/10.1016/S0025-3227(02)00358-4(ISSN 0025-3227).

Zoback, M. D. (2007). Reservoir geomechanics. Cambridge: Cambridge University Press.
Zoback, M. L. (1992). First- and second-order patterns of stress in the lithosphere: The world stress map project. Journal of Geophysical Research Solid Earth, 97(B8), 11703-11728. https://doi. org/10.1029/92JB00132(ISSN 2156-2202).

(Received May 9, 2018, revised August 1, 2018, accepted August 3, 2018, Published online September 3, 2018) 